\title{
Economic Conditions at School Leaving and Sleep Patterns Across the Life Course
}

\author{
${ }^{1}$ Department of Economics, Faculty Research Fellow, National Bureau of Economics, Research Affiliate, Institute for La- \\ bor Economics, Temple University, Ritter Annex 869-1301 Cecil B Moore Avenue, Philadelphia, PA 19122, USA, E-mail: \\ catherine.maclean@temple.edu \\ ${ }^{2}$ School of Sociology, The University of Arizona, Social Sciences Building, Room 400, 1145 E. South Campus Drive, Tucson, AZ, \\ USA, E-mail: tdhill@email.arizona.edu
}

\begin{abstract}
:
We use data drawn from the National Longitudinal Survey of Youth 1979 Cohort to study the effects of leaving school in an economic downturn on sleep quality and quantity. We account for the potential endogeneity of economic conditions at school leaving using instrumental variables based on birth year and early state of residence. We find that men who leave school in an economic downturn initially experience lower quality sleep, but these men are able to experience improved sleep quality over time. Women who leave school in an economic downturn experience better sleep quality, although the effect emerges over time. We find that leaving school in an economic downturn increases sleep quantity among men and women. We document heterogeneity by work type.
\end{abstract}

Keywords: sleep, health production, time allocation, school leaving, economic conditions

JEL classification: I1, I12, J2

DOI: 10.1515/bejeap-2016-0142

\section{Introduction}

Roughly one-third of our time is allocated to sleep (Biddle and Hamermesh 1990); thus, sleep plausibly represents an important economic resource. Indeed, according to the 2014 American Time Use Survey, on working days, full-time workers spend nearly as much time sleeping as they do working: $7.8 \mathrm{~h}$ sleeping versus $9.8 \mathrm{~h}$ working (Bureau of Labor Statistics 2015). ${ }^{1}$ Economic models of the demand for health suggest a role for sleep in the health production function (Grossman 1972). Noneconomic social science studies empirically link sleep, both in terms of its quantity and quality, with a wide range of physical and mental health outcomes (King et al. 2008; Hill, Burdette, and Hale 2009; Cappuccio et al. 2010; Knutson et al. 2010). Literature from across the health sciences suggests that individuals who are sleep deprived (suboptimal quantity) or achieve low-quality sleep (suboptimal quality) have worse health than comparable individuals. Moreover, sleep problems are relatively common. The National Academy of Medicine estimates that 50-70 million American adults suffer from a sleep disorder (Altevogt and Colten 2006).

Sleep deprivation and poor-quality sleep is linked with lower productivity in the labor market (Williamson and Feyer 2000; Baldwin and Daugherty 2004; Landrigan et al. 2004; Daley et al. 2009; Lombardi et al. 2012), increased health-care use (Redline and Newman 2002; Daley et al. 2009), and increased risk of traffic accidents (Monk 1980; Hicks, Lindseth, and Hawkins 1983; Knipling and Wang 1994; Powell et al. 2001). Sleep is believed to be linked with these outcomes through its impact on cognitive performance, decision-making abilities, memory, mood, reaction times, etc. These findings suggest that there may be substantial and negative spillovers from the affected individual to broader society associated with poor sleep outcomes. Surprisingly, there is relatively little economic evidence on factors that determine sleep, either in terms of its quantity or quality. However, individuals appear to value sleep as evidenced by their consumption of medications designed to alleviate sleep disorders (both disorders related to sleep quantity and quality). Approximately $4.1 \%$ of American adults report using a prescription sleep medication in the past 30 days (Chong, Fryar, and Gu 2013) and the costs of these medications exceed $\$ 34$ billion per year. $^{2}$

We examine whether leaving school in an economic downturn influences sleep quality and quantity across the life course. A growing series of economic studies shows that Americans who leave school in an economic downturn have persistently worse labor market (Kahn 2010; Altonji, Kahn, and Speer 2014), marriage market 
(Maclean, Covington, and Sikora Kessler 2015), and health (Maclean 2013 and 2015) outcomes. To the extent that labor market, marriage market, and health experiences impact sleep, or that the same factors predict all outcomes, these findings suggest that there may be a link between leaving school in an economic downturn and sleep. Given the importance of sleep as an independent outcome that reflects an important economic resource and a measure of human well-being, it is important to consider the effects of leaving school in an economic downturn on sleep in addition to the above-noted outcomes.

To explore the effects of leaving school in an economic downturn on sleep, we use data on a long panel of individuals drawn from the National Longitudinal Survey of Youth 1979 Cohort (NLSY79) to model sleep quality and quantity at various points across the adult life course as a function of the state unemployment rate at school leaving. We exploit variation generated by volatility in the United States economy between 1976 and 1998, proxied by state unemployment rates, to identify sleep effects. We address the potential endogeneity of the time and location of school leaving with an instrumental variable model using instruments based on birth year and early state of residence (Kahn 2010). We study heterogeneity in sleep effects across sex, skill (proxied by educational attainment at school leaving), ability (proxied by the Armed Forces Qualifying Exam), and race and ethnicity. We also consider possible mechanisms through which leaving school in an economic downturn impacts sleep. Specifically, we investigate cumulative labor market and marriage market experiences and apply an Oaxaca Blinder (OB) decomposition to study the relative importance of these potential mechanisms.

Our findings suggest a nuanced relationship between the economic conditions experienced at school leaving and sleep across the life course. First, we find evidence that men who leave school in an economic downturn initially experience reductions in sleep quality, but this effect dissipates after 6-10 years in the labor market. Later in their careers, these men eventually experience improvements in sleep quality. Women who leave school during an economic downturn do not experience the initial reduction in sleep quality, but over time they experience improvements in sleep quality relative to comparable women who leave school in stronger economic conditions. In terms of sleep quantity, we find that leaving school in an economic downturn shifts the sleepquantity distribution toward more sleep among both men and women, although our small sample size limits our statistical power in these particular analyses. We document heterogeneity.

\section{Related Literature}

We first review the literature, both noneconomic and economic, that links labor market outcomes with sleep. We then discuss the economic literature on the effects of leaving school in an economic downturn. We combine insights from these literatures to guide our analyses.

\subsection{Noneconomic Social Science Evidence on Individual Labor Market Outcomes and Sleep}

Numerous social science studies outside economics have examined the association between individual labor market outcomes (such as wages, income, occupational prestige, and the probability of employment) and a range of sleep quality and quantity outcomes (Moore et al. 2002; Paine et al. 2004; Gellis et al. 2005; Lauderdale et al. 2006; Friedman et al. 2007; Stamatakis, Kaplan, and Roberts 2007; Krueger and Friedman 2009; Grandner et al. 2010; Soltani et al. 2012; Pfeifer 2015). These studies collectively suggest that employed and higher wage and income individuals tend to exhibit more favorable sleep outcomes than unemployed and lower wage and income individuals.

The hypothesized process is that psychobiological factors (e.g. stress, allostatic load, anxiety, depression) associated with poor labor market outcomes impede an individual's ability to achieve desirable sleep, both in terms of its quantity and quality. To this point, the social science literature outside of economics has not incorporated economic factors (time costs, income effects, work time, etc.) into the modeling of sleep outcomes.

\subsection{Economic Theory and Evidence on the Relationship Between Economic Conditions and Sleep}

Biddle and Hamermesh (1990) build on Becker's seminal theory of time allocation (Becker 1965) and develop a model of sleep allocation. ${ }^{3}$ Prior to this effort, economists treated sleep time as an exogenous variable in economic models. Thus, the central contributions of Biddle and Hamermesh (1990), henceforth "BH," are to endogenize sleep time allocation choices and explore economic factors that predict the demand for sleep time (i.e. wages, income, and time allocated to work). The BH model assumes that sleep directly enters the consumer's utility function and impacts labor market productivity (i. e. wages). ${ }^{4}$ 
For the purposes of our study, it is important to note that the BH model focuses exclusively on the quantity of sleep and therefore does not offer predictions for sleep quality. ${ }^{5}$ Thus, the model does not differentiate between high- and low-quality sleep. The BH model predicts that both wage and income have ambiguous impacts on sleep quantity. Instead, the net effect of these variables on sleep quantity is determined by the relative strength of various offsetting relationships between model variables. In an empirical analysis of time use data, $\mathrm{BH}$ demonstrate that the demand for sleep is declining in wages and time spent working but unrelated to income, and wage effects are stronger for men than for women. ${ }^{6}$

Conceptually, sleep quality could have two offsetting effects on sleep quantity. First, if need for sleep is related to the need to accumulate a specific amount of energy (where energy is a stock variable that can be replenished through investment), then individuals who have low sleep quality may need to sleep for longer periods of time that comparable individuals who have high-quality sleep to accumulate energy stock. Second, energy stock replenishment that occurs during sleep time can be viewed as the "returns to sleeping." Taking this view, low-quality sleep offers lower returns to individuals, which suggests that such individuals will sleep less.

Related to our work, a handful of studies have examined the relationship between contemporaneous economic conditions and sleep. Using the American Time Use Survey (ATUS), Antillón, Lauderdale, and Mullahy (2014) find that sleep quantity increases modestly during recessions: a 1 percentage point increase in the state unemployment rate leads to a 0.83 -min increase in daily sleep. These findings are supported by research using Canadian (Brochu, Armstrong, and Morin 2012) and Icelandic (Ásgeirsdóttir et al. 2014 and 2016) data. On the other hand, Ásgeirsdóttir and Ólafsson (2015) who also use the ATUS data find no evidence of a relationship between economic conditions and sleep quantity while Pabilonia (2014) provides evidence using the ATUS that teens sleep less when economic conditions deteriorate. Thus, the relationship between sleep quantity and economic conditions appears to be context and population specific. To the best of our knowledge, only one economic study explores the relationship between contemporaneous economic conditions and sleep quality. Antillón, Lauderdale, and Mullahy (2014) demonstrate that reports of restless sleep, a measure of poor sleep quality, declines during economic downturns.

\subsection{The Impact of Leaving School in an Economic Downturn on Labor Market, Marriage Market, Fertility, and Health Outcomes}

Workers who leave school in an economic downturn may be directed toward low wage and otherwise less desirable jobs in the short run (Reder 1955; Okun 1973; McLaughlin and Bils 2001). This initial employment obstacle has been shown to persist over time (Oyer 2006 and 2008; Genda, Kondo, and Ohta 2010; Kahn 2010; Kwon, Milgrom, and Hwang 2010; Schoar and Zuo 2011; Liu, Salvanes, and Sorensen 2012; Oreopoulos, Von Wachter, and Heisz 2012; Maclean 2014; Altonji, Kahn, and Speer 2016). ${ }^{7}$ For example, workers who leave school in an economic downturn tend to earn lower wages, have lower earnings, to hold less prestigious jobs, and are less likely to be promoted. Using the National Longitudinal Survey of Youth, the same data we employ, Kahn (2010) finds that a 1 percentage point increase in the school-leaving state unemployment rate leads to a $9.1 \%$ reduction in the hourly wage and that this effect is observable for 15 years after school leaving among white, male college graduates.

Kahn (2010) provides additional evidence that workers who leave school in an economic downturn may attempt to offset reduced wages by increasing labor supply (measured by any employment and annual weeks worked) over time. Alternatively, Genda, Kondo, and Ohta (2010) find evidence that leaving school in an economic downturn reduces employment propensities for up to 12 years while Altonji, Kahn, and Speer (2016) document reduced employment propensity, hours worked, and fulltime employment propensity among college graduates who leave school when the state unemployment rate is high. Thus, the extent to which work time over the life course is impacted by leaving school in an economic downturn may vary across sample and time period. While the literature overall suggests that labor market effects are persistent, they are perhaps not permanent and appear to dissipate within 10-15 years in the labor market.

The career effects attributable to leaving school in an economic downturn are not homogenous across workers. Genda, Kondo, and Ohta (2010) find more persistent wage penalties for college graduates than high school graduates among men in US labor markets, ${ }^{8}$ and Hershbein (2012) shows that high school graduates are less impacted by economic conditions at school leaving than higher skill workers. Finally, Kondo (2015) documents that the wage penalties due to leaving school in an economic downturn are weaker for women than for men, but she does not document differences across race and ethnicity.

The career penalties attributable to leaving school in an economic downturn have also been shown to impact marriage outcomes (Hershbein 2012; Hofmann and Hohmeyer 2014; Maclean, Covington, and Sikora Kessler 2015). For example, American men who leave school in an economic downturn are persistently less likely to 
marry and have children than comparable men who leave school under more favorable economic conditions (Maclean, Covington, and Sikora Kessler 2015).

A series of studies link economic conditions at school leaving with a range of health-related outcomes across the life course, including overall reported health, mental health, risky drinking practices, and body weight, and outcomes that reflect internal resources such as self-esteem (Maclean 2013; Cutler, Huang, and LlerasMuney 2015; Guo and Hai 2015; Maclean 2015; Maclean and Hill 2015). The hypothesized relationship between leaving school in an economic downturn and these outcomes is that the labor and marriage market penalties attributable to leaving school in an economic downturn eventually impact outcomes such as health and selfesteem. Although there is heterogeneity across studies, the findings suggest that American adults, especially men, who leave school when the state unemployment rate is high tend to have worse health.

A recent study by Guo and Hai (2015) uses data from the National Longitudinal Survey of Youth 1997 to examine the effects of leaving school in an economic downturn on sleep quantity along with several other health outcomes and health behaviors. The authors find that high-school graduates who leave school in an economic downturn increase their sleep duration. We build on the work of Guo and Hai (2015) in two important ways. We model measures of sleep quantity and quality, and we examine a long panel of individuals which allows us to explore effects through middle age. Specifically, we are able to track adults into their 50s. The NLSY97 sample members [who are studied by Guo and Hai (2015)] left school during the late 1990s and early 2000s, this time period was characterized by a relatively strong economy. Our sample of school leavers left school during the severe recession of the early 1980s, which is the largest economic downturn in the post-World War II era prior to the recent 2008-2010 recession. With this cohort contrast in mind, our findings may be useful for thinking through the implications for those individuals who left school during the 2008-2010 recession. Taken together, these two studies complement each other and broaden our understanding of the lifetime consequences of leaving school in an economic downturn for sleep outcomes.

\subsection{Hypotheses}

We hypothesize that the key channels through which leaving school in an economic downturn may impact sleep are wages, earnings, labor supply, marriage, fertility, and health. We next discuss the specific predictions that we will test in the data.

Sleep quality: Success in the labor market (defined by a broad set of factors including wages, employment, income, occupational prestige, promotions, etc.) is empirically linked with sleep quality, and individuals who leave school in an economic downturn have persistently diminished wages, earnings, promotion propensity, and occupational prestige. Leaving school in an economic downturn contributes to worse health outcomes in general and mental illness and risky drinking practices in particular (Maclean 2013 and 2015; Maclean and Hill 2015). Poor mental health and risky drinking can undermine sleep quality (Roehrs and Roth 2001; Kaneita et al. 2009; Popovici and French 2013). Therefore, we expect that those individuals who left school when the state unemployment rate was high will have worse sleep quality through the noted mechanisms of wages, earnings, employment, and health. We suspect that this negative effect will be muted for men because men who leave school in an economic downturn are less likely to have children (Maclean, Covington, and Sikora Kessler 2015), and children are predicted to reduce sleep quality (Asgeirsdottir and Zoega 2011).

Sleep quantity: The direction of the relationship between leaving school in an economic downturn and sleep quantity is ambiguous. The economic literature suggests that those who leave school in an economic downturn tend to initially earn lower wages (which all else equal reflects the price of sleep) and income (which impacts the consumer's budget), which may increase or decrease sleep quantity at least during the period in which these individuals experience lower wages and income. Sleep quantity will increase if standard wage and income effects dominate, if the opportunity cost of sleep is the wage and sleep is a normal good. However, as $\mathrm{BH}$ point out, there are several offsetting factors. Reduced wages may reduce sleep quantity. Income may also be unrelated to sleep. ${ }^{9}$ To offset lower wages, workers who leave school in an economic downturn may over time increase time spent working, ${ }^{10}$ which should decrease time spent sleeping.

Finally, the economic literature suggests that men who leave school in an economic downturn are less likely to marry and have children. If marriage promotes optimal sleep (Hale 2005), this pathway would suggest that those who leave school in an economic downturn (especially men) will sleep less. However, if men who leave school in an economic downturn are less likely to have children, they may sleep more without childrearing responsibilities. ${ }^{11}$ 


\section{Data, Variables, and Methods}

\subsection{Data}

We draw data on a long panel of individuals from the NLSY79 Cohort. In particular, we use the geocoded data which allows us to access state of residence. The original sample consists of 12,686 youth 14-22 in 1979. The survey was administered annually by the Bureau of Labor Statistics between 1979 and 1993 and biannually from 1994 to 2012. We utilize measures of the annual state unemployment rate using the Bureau of Labor Statistics Local Area Unemployment Database.

\subsection{Sleep Measures}

To measure sleep quality, we rely on an item contained in the Center for Epidemiologic Studies Depression (CESD) index. The CESD is a validated measure of depressive symptoms (Radloff 1977; Kohout et al. 1993) that is commonly used in the economics literature to study mental health (Falba, Sindelar, and Gallo 2009; Maclean 2013; McInerney, Mellor, and Nicholas 2013; Ayyagari and Shane 2015; Sabia and Rees 2015). Our specific indicator of sleep quality is a single item: "During the past week, my sleep was restless: 1) rarely, none of the time, or one day; 2) some of the time, a little of the time, or 1 to 2 days; 3) occasionally, a moderate amount of the time, or 3 to 4 days; and 4 ) most of the time, all of the time, or 5 to 7 days." We use the ordinal score (0-3, with higher scores indicating more restless sleep) and an indicator for occasionally or most of the time experiencing restless sleep (equal to 1 if the respondent reported value 2 or 3 , and 0 otherwise).

This item is a reasonable indicator of sleep quality even though it is reported by the respondent. According to the National Sleep Foundation (2015), unrefreshing sleep and nonrestorative sleep are symptoms of insomnia. ${ }^{12}$ Restless sleep is also conceptually related to a range of adverse sleep outcomes, including difficulty falling asleep, difficulty staying asleep, waking up too early, fatigue, sleep inefficiency, and poor overall sleep quality. Moreover, our use of reported sleep problems is consistent with clinical practice as health-care professionals identify sleep problems using patient reports of symptoms (National Institutes of Health 2012). For example, in clinical practice, health-care providers will ask patients how often patients awaken during the night, how long it takes patients to fall sleep, how well rested patients feel upon awakening, and how alert patients feel during the day.

The CESD restless sleep item is also similar to, or conceptually related to, items from several established sleep inventories, including, for example, the Sleep Disorders Inventory ("Are you bothered by restless or fitful sleep?"), the Pittsburgh Sleep Quality Index ("Wake up in the middle of the night or early morning?"), and the Iowa Sleep Disturbances Inventory ("I have trouble staying asleep."). The CESD restless sleep item has been used as a sleep quality outcome in previous research (Kutner et al. 2001). This item has even been used to validate the Pittsburgh Sleep Quality Index (Carpenter and Andrykowski 1998).

The CESD is asked four times in the NLSY79: 1992, 1994, the Age 40 Health Module (completed in 1998, 2000, 2002, 2004, or 2006 depending on respondent age), and the Age 50 and Older Health Module (completed in 2008, 2010, or 2012 depending on respondent age). We have up to four observations per respondent. We have valid data on the restless sleep question for 4,001 unique men and 4,098 unique women. We rely on the unbalanced NLSY79 sample (Kahn 2010) and thus have data on 13,479 male/year and 14,124 female/year observations.

To measure sleep quantity, we use a standard measure of reported sleep duration contained in the Age 50 and Older Health Module (Hill et al. 2014; Guo and Hai 2015). Respondents are asked "How much sleep do you usually get at night (or in your main sleep period) on weekdays or workdays?" We construct indicators for the following nightly weekday or workday sleep durations: less than $5 \mathrm{~h}, 5$ to less than $6 \mathrm{~h}, 6$ to less than $7 \mathrm{~h}, 7$ to less than $8 \mathrm{~h}, 8$ to less than $9 \mathrm{~h}$, and 9 or more hours.

\subsection{School-Leaving Economic Conditions}

The key explanatory variable in this study is the economic conditions at school leaving. To capture this variable, we must first locate the school-leaving period. The school-leaving definition includes both students who graduated with a degree and who dropped out prior to degree completion (i. e. both graduates and dropouts). We use responses to education history questions fielded between 1979 and 1998 to identify the year in which the respondent left school. We exclude all respondent/year observations for which the sleep outcome predates the school-leaving year. ${ }^{13}$ We require that respondents report being out of school for a period of 2 years after school leaving to avoid incorrectly classifying short departures (e. g. sickness, travel) as true school leaving. 
We use geocodes to determine the school-leaving state. Respondents who left school between 1976 and 1978 are assigned the 1979 interview state. This imputation assumes that individuals do not move across state lines between school leaving and the 1979 interview. ${ }^{14}$ The interview state is assigned to respondents who left school between 1979 and 1998 .

Appendix Table 26 reports school-leaving cohort size in each year between 1976 and 1998. The largest schoolleaving cohort is 1979 with 1,171 school leavers and the smallest cohort is 1998 with 2 school leavers. Many respondents left school in the early 1980s, which covered the severe recession of 1981-1982 (National Bureau of Economic Research 2010). We proxy economic conditions with the school-leaving state unemployment rate because this is the standard measure in the literature (Kahn 2010; Altonji, Kahn, and Speer 2016). ${ }^{15}$

\subsection{Control Variables}

We include a set of predetermined variables that are expected to predict sleep outcomes in all regression models: race and ethnicity (African-American and Hispanic, with White as the omitted group), a proxy for ability (age standardized Armed Forces Qualification Test [AFQT]), ${ }^{16}$ parental education as measured by mother's and father's years of education entered linearly and separately, and three indicators for access to cultural materials within the household at age 14 (library card, newspapers, and magazines).

We include indicators for missing covariates and assign missing observations the sample mean (continuous variables) or mode (binary variables) in our regression models. Results are robust if we instead drop all observations with missing information on covariates or if we do not include these control variables in the regression model. In addition, we include the number of years (entered linearly) between the school-leaving period and the periods in which sleep quality is measured. This variable is our proxy for potential experience in the labor market (Kahn 2010). We do not include variables that are plausibly influenced by leaving school in an economic downturn (e.g. current wages) as control variables in our regressions to avoid bias from including "bad controls" (Angrist and Pischke 2009).

\subsection{Empirical Model}

Equation 1 presents our regression model:

$$
S L_{i s t g}=\alpha_{0}+\alpha_{1} P E_{i g-t}+\sum_{b=2}^{b=7} \alpha_{b} U E_{s t}+\alpha_{8}^{\prime} X_{i}+\alpha_{9}^{\prime} S_{s}+\alpha_{10}^{\prime} D_{t}+\alpha_{11}^{\prime} G_{g}+\varepsilon_{i s t g}
$$

$S L_{i s t g}$ is a sleep outcome measured for individual $i$ in school-leaving state $s$ and school-leaving year $t$ measured in survey year $g . P E_{i g-t}$ is potential labor market experience (i. e. the number of years between school leaving and the survey year in which a sleep variable is measured). We seek to understand dynamics in the relationship between economic conditions at school leaving and sleep outcomes across the life course. To this end, we follow insight offered by Kondo (2015) and interact the annual state unemployment rate in school-leaving state $s$ in school-leaving year $t$ with indicator variables for 1-5, 6-10, 11-15, 16-20, 21-25, and 26-37 years of potential experience. ${ }^{17}$ These variables are reflected by the terms $\sum_{b=2}^{b=7} \alpha_{b} U E_{s t}$ in eq. 1). We have very few observations that we observe within 5 years of school-leaving and we are concerned that estimating regression coefficients using a small numbers of observations may lead to inconsistent estimates. Therefore, we suppress the coefficient estimate on the 1-5 years post school-leaving indicator in all analyses. ${ }^{18}$

$X_{i}$ is a vector of time invariant personal characteristics (race and ethnicity, ability, parental education, and access to cultural materials within the home at age 14). $S_{s}$ and $D_{t}$ are vectors of school-leaving state and year fixed effects. Inclusion of the school-leaving state fixed effects implies that we use within school-leaving state variation in unemployment rates to identify treatment effects. ${ }^{19}$

We utilize OLS for continuous outcomes and linear probability models for binary outcomes. We estimate regression models separately for men and women given different labor market participation patterns (Blau and Kahn 2007) and different labor market and marriage market effects due to leaving school in an economic downturn (Kondo 2015; Maclean, Covington, and Sikora Kessler 2015). We apply that NLSY79 sample weights but unweighted results are not appreciably different (Solon, Haider, and Wooldridge 2015).

We cluster standard errors around the school-leaving state. Our analysis sample emits 51 cluster cells (school-leaving states) in the male sample and 49 cluster cells in the female sample. The number of cluster cells falls in subgroup analyses (detailed later in the manuscript), but the number of cluster cells ranges from 38 to 48 in these regressions. We report the number of cluster cells emitted by the data in each regression in 
the tables. We believe that we are able to estimate consistent standard errors in our data (Cameron and Miller 2015).

\subsection{Identification}

Identification of eq. 1 requires that the state unemployment rate at school leaving is uncorrelated with the error term in the sleep equations after we condition on personal characteristics and various fixed effects. A concern is that the time or location of school leaving is endogenous to the school-leaving state unemployment rate which would violate our identifying assumption. For example, school leavers may attempt to avoid leaving school in an economic downturn by enrolling in additional schooling or moving. On the other hand, some individuals may drop out of school to pursue employment opportunities in economic upturns. We refer to these behaviors collectively as "endogenous sorting."

The bias attributable to endogenous sorting is difficult to sign. School leavers who avoid economic downturns may have unobservable characteristics (e. g. time preferences) that permit avoidance behavior. An additional concern is measurement error in the school-leaving variables because we rely on individuals' reports of year of school leaving, which may be reported with error, and we must impute the school-leaving state for some individuals. The impact of such error on regression coefficients is also difficult to sign (Bound, Brown, and Mathiowetz 2001). Thus, ex ante the direction of bias from these various and potentially offsetting sources is not clear.

We rely on two stage least squares (2SLS) to address such sources of bias. We select instruments based on birth year and state of residence at age 14 (Kahn 2010). The IVs assume that respondents adhere to normal school starting ages and progression through school. We refer to our IV as the "on time" state unemployment rate. These instruments have been applied in previous investigations into the life course consequences of leaving school in an economic downturn (Kahn 2010; Maclean 2013 and 2015; Maclean and Hill 2015).

The on time IV utilizes state unemployment rate variation that is generated exogenously by birth year and state of residence at age 14. For example, we assign a 4-year college graduate the annual state unemployment rate in the year she turned 22 (age 22 is the modal age for 4-year college graduates in our sample) in the state of residence at age 14 (parents or caregivers likely determine state of residence early in life rather than school leavers themselves). We make similar IV assignments for all educational levels regardless of whether or not the respondent left school with a standard educational credential (e.g. high school diploma or 4-year college degree). ${ }^{20}$ We exclude respondents who did not reside in the United States at age 14 because we cannot match them to a state of residence and use historical compulsory schooling laws to calculate school start dates (Acemoglu et al. 2001). We assign the modal school starting age in our sample (7 years) to respondents not born in the United States.

One may be concerned that the instrument is more accurately measured for credentialed school leavers (those adults who leave school with a high school diploma or a 4-year college degree) than for those who left school without a credential (dropouts) and school leavers who obtain a less common educational credential (e. g. a 2-year college degree or Masters' degree). We address this potential concern later in the manuscript by separately estimating our regression models on a "standard credential" sample (i. e. respondents who leave school with a high school diploma or a 4-year college degree) and a "nonstandard credential" sample (all other respondents, including dropouts). We chose to retain all respondents regardless of their educational attainment in the analytic sample to account for the possibility that economic conditions impact the level of completed schooling and that stratifying the sample on this variable can lead to bias in regression coefficients.

A related concern is that the instruments may be more or less likely to satisfy the exclusion restriction for standard credential school leavers and nonstandard credential school leavers (as we have defined these groups). For example, it is plausible that individuals who leave school without a standard credential may be more responsive to economic conditions in terms of the decision to remain in school than other school leavers. Such behavior may lead nonstandard credential school leavers to drop out during downturns, and if education impacts sleep, then the exclusion restriction may be violated. On the other hand, if individuals who leave school with a standard credential are more likely to stay in school to complete their credential during economic downturns, then this behavior may also lead to a violation of the exclusion restriction. We note the potential differential likelihood of the exclusion restriction violation by educational credentials as a limitation of the study.

Without further assumptions, the causal effect estimated by an instrumental variable model is the causal effect for compliers only. In other words, an instrumental variable model estimates the local average treatment effect. In our study, compliers are individuals who do not alter their education profile or state of residence in response to economic conditions at school leaving. The generalizability of our 2SLS estimates to other individuals is not clear.

Potential labor market experience and the interaction terms between potential experience and the schoolleaving state unemployment rate indicator variables are also potentially endogenous in eq. 1 due to endogenous 
sorting. We therefore instrument these variables. First, we instrument potential labor market experience with potential experience implied by the instrument. For example, if a respondent is 41 in 2006 and left school with a college degree, the potential experience implied by the on time instrument is 19 years. We define this variable similarly (i. e. using the difference between age at the survey year in which sleep is measured and age at on-time school leaving as outlined earlier in this section) for all other individuals regardless of whether they left school with a standard credential, a nonstandard credential, or no credential. Second, we instrument the interaction terms with the instrument interacted with comparable potential experience indicator variables implied by the instrument.

In our 2SLS models, we cluster standard errors around the state of residence at age 14 . This means that the number of clusters emitted by the data varies across OLS and 2SLS models as the school-leaving state differs from the on time school-leaving state for some respondents. We also replace school-leaving state and year fixed effects with state of residence at age 14 and on time year fixed effects in our 2SLS models to account for omitted variables (Maclean 2013).

\subsection{Mechanisms}

To understand the mechanisms that may link leaving school in an economic downturn to sleep outcomes, we use data in the NLSY79 on cumulative labor market and marriage market outcomes. We first regress several cumulative labor and marriage market outcomes on the school-leaving unemployment rate to understand how our potential mechanisms are impacted by school-leaving state unemployment rates. For brevity, we focus on 2SLS results generated in the sleep quality sample. ${ }^{21}$ Second, we conduct a OB decomposition analysis to understand the relative importance of labor market and marriage market outcomes for sleep outcomes (Blinder 1973; Oaxaca 1973).

The OB decomposition is used to study differences in outcomes across groups. Although the original applications explored wage differentials across groups the method can be applied to understand why two groups have differences in a wide range of outcome variables, including health variables (Kirby, Taliaferro, and Zuvekas 2006; Powell et al. 2012). In our context, we compare individuals in the top and bottom halves of the empirical distribution of our sample of school-leaving state unemployment rates. We apply the OB decomposition as follows:

$$
\overline{S L}_{L}-\overline{S L}_{H}=\bar{X}_{L}^{\prime} \hat{\beta}_{L}-\bar{X}_{H}^{\prime} \hat{\beta}_{H}=\left(\bar{X}_{L}^{\prime}-\bar{X}_{H}^{\prime}\right) \hat{\beta}-\bar{X}^{\prime}\left(\hat{\beta}_{L}-\hat{\beta}_{H}\right)=(\text { explained })+(\text { unexplained })
$$

where $L$ and $H$ indicate the samples that left school when the state unemployment rate was low (at or below the sample mean) and high (above the sample mean). $\overline{S L}_{L}$ and $\overline{S L}_{H}$ are the mean sleep values for these two groups. $\bar{X}_{L}^{\prime}$ and $\bar{X}_{H}^{\prime}$ are the mean values of the included control variables and $\hat{\beta}_{L}$ and $\hat{\beta}_{H}$ are the associated regression coefficient estimates. $\bar{X}^{\prime}$ and $\hat{\beta}$ are weighted averages of the group specific means and regression coefficient estimates.

The OB method decomposes the differences in sleep quality between the two groups into those due to group differences in the mean values of the included covariates ("endowments") and those differences across the groups in terms of the estimated coefficients ("returns"). We follow Neumark (1988) and use the estimated coefficients from a pooled regression (i. e. including individuals in both groups as defined by the school-leaving state unemployment rate in the sample and including an indicator variable for group status in the regression model) to obtain the weighted average for $\hat{\beta}$. We also transform the coefficients on categorical variables (e.g. race and ethnicity) included in the regression model such that the decomposition results are insensitive to the choice of the omitted category.

In eq. 2), the explained portion of the difference in sleep quality outcomes is determined by differences in endowments of the included covariates $(X)$. The unexplained portion is determined by the differences in the estimated coefficients (returns). Thus, the unexplained portion of the difference in sleep quality outcomes can be interpreted as the differential response to sleep quality determinants (i. e. included covariates) by the groups. However, the unexplained portion also reflects other unobserved differences between groups.

Of particular interest is the contribution of labor market and marriage market mechanisms. We consider the following labor market mechanisms: earnings from salary and wages, number of jobs held, and weeks worked. The marriage market mechanisms are as follows: number of partners and number of children. ${ }^{22}$ These variables are cumulative from the period of school-leaving through the survey year in which sleep is measured. ${ }^{23}$ We focus on OLS regressions in the decomposition analysis, but results based on 2SLS are available on request from the corresponding author. ${ }^{24}$ We note that the labor market and marriage market outcomes are likely influenced by leaving school in an economic downturn, so the causal interpretation of our decomposition analysis is not clear (Angrist and Pischke 2009). 


\section{Results}

\subsection{Summary Statistics}

Summary statistics are reported in Table 1 (sleep quality sample) and 2 (sleep quantity sample). Although the sleep quality regression models we use up to four observations per respondent, we include only one observation per respondent in Table 1 (specifically, we use the first observed measure, which is typically measured in 1992 or 1994). On average, the sleep quality score is 0.65 among men and 0.82 among women (this variable ranges from 0 to 3). The share of men in our sample reporting frequent restless sleep is $16.9 \%$ while $22.6 \%$ of women in our sample report this sleep outcome. The average state unemployment rate at school leaving is $7.5 \%$ among both men and women. Men left school 12.7 years prior to measurement of the sleep outcomes and women left school 11.6 years prior. Demographics of the analytic sample are comparable to an older sample such as the NLSY79.

Table 1: Summary statistics for sleep quality sample: NLSY79.

\begin{tabular}{lll}
\hline Sample & Men & Women \\
\hline Sleep quality outcomes & & \\
Restless sleep (0-3) & 0.6477 & 0.8167 \\
Frequent restless sleep (0/1) & 0.1688 & 0.2263 \\
School-leaving economic conditions & & \\
State unemployment rate & 7.4992 & 7.5079 \\
Demographics & & \\
Years since school leaving & 12.709 & 11.595 \\
White & 0.8004 & 0.8044 \\
African-American & 0.1373 & 0.1365 \\
Hispanic & 0.0623 & 0.0591 \\
Mother's education & 12.010 & 11.818 \\
Father's education & 11.763 & 11.628 \\
Age adjusted AFQT score & -0.0790 & -0.1093 \\
Library card in the home at age 14 & 0.7478 & 0.7830 \\
Magazines in the home at age 14 & 0.6791 & 0.6705 \\
Newspapers in the home at age 14 & 0.8441 & 0.8317 \\
Observations & 4,001 & 4,098 \\
\hline
\end{tabular}

Notes: Sample includes one observation per respondent. NLSY79 weights applied.

In terms of sleep quantity (Table 2), we find that $6.0 \%$ of men sleep less than $5 \mathrm{~h}$ per night, $10.4 \%$ sleep 5 to less than $6 \mathrm{~h}$ per night, $27.5 \%$ sleep $6 \mathrm{~h}$ to less than $7 \mathrm{~h}$ per night, $32.4 \%$ sleep $7 \mathrm{~h}$ to less than $8 \mathrm{~h}$ per night, $20.6 \%$ sleep 8 to less than $9 \mathrm{~h}$ per night, and $3.1 \%$ sleep 9 or more hours per night. Among women, these shares are $5.4 \%, 9.6 \%, 25.8 \%, 31.2 \%, 23.5 \%$, and $4.4 \%$. Thus, the majority of the sample reports sleeping between 6 and $9 \mathrm{~h}$ per week night.

Table 2: Summary statistics for sleep quantity sample: NLSY79.

\begin{tabular}{lll}
\hline Sample & Men & Women \\
\hline Sleep quantity outcome variables & & \\
Sleep less than 5 h per night & 0.0604 & 0.0541 \\
Sleep 5 to less than 6h per night & 0.104 & 0.0964 \\
Sleep 6 to less than 7 h per night & 0.275 & 0.258 \\
Sleep 7 to less than 8 h per night & 0.324 & 0.312 \\
Sleep 8 to less than 9h per night & 0.206 & 0.235 \\
Sleep 9 or more hours per night & 0.0306 & 0.0439 \\
School-leaving economic conditions & & \\
State unemployment rate & 7.479 & 7.590 \\
Demographics & & \\
Years since school leaving & 31.47 & 31.76 \\
White & 0.804 & 0.811 \\
African-American & 0.136 & 0.133 \\
Hispanic & 0.0602 & 0.0555 \\
Mother's education & 11.75 & 11.66
\end{tabular}


Father's education

Age adjusted AFQT score

Library card in the home at age 14

Magazines in the home at age 14

Newspapers in the home at age 14

Observations

$\begin{array}{ll}11.99 & 11.82 \\ 0.0388 & -0.0359 \\ 0.759 & 0.797 \\ 0.681 & 0.667 \\ 0.863 & 0.856 \\ 2,361 & 2,565\end{array}$

11.99

2,361
11.82

0.797

0.667

2,565

Notes: Sample includes one observation per respondent. NLSY79 weights applied.

\subsection{OLS Regression Results for Sleep Quality}

Table 3 reports OLS estimates of the effect of leaving school in an economic downturn on sleep quality among men and women. Our findings suggest that men who leave school in an economic downturn have lower sleep quality than comparable men who did not leave school in an economic downturn. The observed effects for men dissipate after 10-15 years in the labor market. More specifically, a 1 percentage point increase in the schoolleaving state unemployment rate leads to a 0.03 unit (4.1\%) increase in restless sleep that persists 6-10 years after school leaving. In terms of the probability of reporting frequent restless sleep, a 1 percentage point increase in the school-leaving state unemployment rate leads to a 1.3 percentage point $(7.9 \%)$ increase in the probability of reporting frequent restless sleep $6-10$ years after school leaving and a 0.8 percentage point $(4.7 \%)$ increase in this probability 11-15 years after school leaving. The coefficient estimates on more distal potential experience indicators are small in magnitude and are not statistically different from zero, suggesting that sleep quality effects dissipate by 15 years after school leaving.

Table 3: Effect of economic conditions faced at school leaving on sleep quality: NLSY79 OLS model.

\begin{tabular}{|c|c|c|}
\hline Outcome & Restless sleep (0-3) & Frequent restless sleep \\
\hline \multicolumn{3}{|l|}{ Men } \\
\hline Sample mean/Proportion & 0.6477 & 0.1688 \\
\hline \multirow[t]{2}{*}{$6-10$ years potential experience } & $0.0266^{* * *}$ & $0.0134^{* * *}$ \\
\hline & $(0.0097)$ & $(0.0040)$ \\
\hline \multirow[t]{2}{*}{$11-15$ years potential experience } & 0.0144 & $0.0079^{* *}$ \\
\hline & $(0.0087)$ & $(0.0035)$ \\
\hline \multirow[t]{2}{*}{$16-20$ years potential experience } & 0.0029 & 0.0037 \\
\hline & $(0.0086)$ & $(0.0032)$ \\
\hline \multirow{2}{*}{ 21-25 years potential experience } & -0.0059 & 0.0009 \\
\hline & $(0.0100)$ & $(0.0035)$ \\
\hline \multirow[t]{2}{*}{ 26-37 years potential experience } & 0.0018 & 0.0032 \\
\hline & $(0.0126)$ & $(0.0042)$ \\
\hline Observations & 13,479 & 13,479 \\
\hline Clusters & 51 & 51 \\
\hline \multicolumn{3}{|l|}{ Women } \\
\hline Sample mean/proportion & 0.8167 & 0.2263 \\
\hline \multirow{2}{*}{$6-10$ years potential experience } & -0.0006 & -0.0000 \\
\hline & $(0.0112)$ & $(0.0038)$ \\
\hline \multirow[t]{2}{*}{$11-15$ years potential experience } & -0.0064 & -0.0028 \\
\hline & $(0.0098)$ & $(0.0036)$ \\
\hline \multirow[t]{2}{*}{ 16-20 years potential experience } & -0.0146 & -0.0053 \\
\hline & $(0.0108)$ & $(0.0043)$ \\
\hline \multirow[t]{2}{*}{ 21-25 years potential experience } & -0.0142 & -0.0046 \\
\hline & $(0.0109)$ & $(0.0046)$ \\
\hline \multirow[t]{2}{*}{ 26-37 years potential experience } & 0.0027 & 0.0012 \\
\hline & $(0.0119)$ & $(0.0054)$ \\
\hline Observations & 14,124 & 14,124 \\
\hline Clusters & 47 & 47 \\
\hline
\end{tabular}

\section{***; **; and * = statistically different from zero at the $1 \% ; 5 \%$; and $10 \%$ level, respectively.}

Notes: All models estimated with OLS and control for potential experience, demographics, school-leaving state fixed effects, and school-leaving year fixed effects. NLSY79 sample weights applied. Standard errors reported in parentheses and clustered around the school-leaving state. 
Coefficient estimates are not statistically different from zero in the female regressions. However, the majority of the coefficient estimates are negative suggesting that women who leave school in an economic downturn may experience better sleep quality.

\subsection{Instrumental Variables}

The key empirical challenge we face is bias from endogenous sorting and measurement error. To address these potential sources of bias, we estimate 2SLS models. Before proceeding to the 2SLS analysis, we provide evidence on the suitability of our selected instruments.

Table 4 presents results from first stage regressions: the school-leaving state unemployment rate is regressed on the IVs and other covariates included in eq. 1 using OLS. For brevity, we report regressions of the continuous school-leaving state unemployment rate on the continuous instrumental variable (the on time school-leaving state unemployment rate) rather than the categorical variables utilized in the regressions. The IV is a strong predictor of the school-leaving state unemployment rate: the $F$ statistic is approximately 62 in the male sample and 43 in the female sample, both above minimum thresholds suggested by Stock and Yogo (2005). Quantitatively, a 1 percentage point increase in the on time state unemployment rate is associated with a 0.28 percentage point (roughly $3.7-3.8 \%$ ) increase in the school-leaving state unemployment rate in the male and female samples $(p<0.01)$.

Table 4: First stage OLS regressions: NLSY79.

\begin{tabular}{lll}
\hline Sample & Men & Women \\
\hline Sample mean & 7.4992 & 7.5079 \\
On time state unemployment rate & $0.2826^{* * *}$ & $0.2805^{* * *}$ \\
& $(0.0363)$ & $(0.0430)$ \\
F statistic on the on time & $60.46(0.0000)$ & $42.53(0.0000)$ \\
school-leaving state unemployment & & \\
rate $(p$ value) & 13,479 & 14,124 \\
Observations & 51 & 47 \\
Clusters & & \\
\hline
\end{tabular}

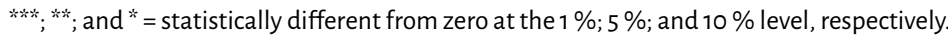

Notes: The outcome variable in all regressions in the school-leaving state unemployment rate. All models estimated with OLS and control for potential experience, demographics, on time school-leaving state fixed effects, and on time school-leaving year fixed effects. NLSY79 sample weights applied. Standard errors reported in parentheses and clustered around the school-leaving state.

Table 5 presents results from the 2SLS models for men and women. The results present a more nuanced relationship between leaving school in an economic downturn and sleep quality than was revealed in the OLS regressions. First, among men, we find evidence that leaving school in an economic downturn leads to an initial increase in the probability of reporting restless sleep but, over time, this pattern is reversed and men who leave school in an economic downturn are less likely to experience restless sleep than comparable men who did not leave school in an economic downturn. Overall, the male 2SLS results suggest an inverted U-shaped relationship between leaving school in an economic downturn and restless sleep. In particular, a 1 percentage point increase in the school-leaving state unemployment rate leads to 0.015 unit $(2.3 \%)$ increase in the restless sleep score and a 1.4 percentage point $(8.2 \%)$ increase in the probability of reporting frequent restless sleep 6-10 years after school leaving (the coefficient estimate in the restless sleep score is not statistically different from zero). Over time, however, the direction of the relationship changes. By 16-20 years after school leaving, men who leave school in an economic downturn are less likely to report restless sleep. More specifically, a 1 percentage point increase in the school-leaving state unemployment rate leads to a 0.023 unit $(3.5 \%)$ decrease in the restless sleep score and a 0.37 percentage point $(2.2 \%)$ reduction in the probability of reporting frequent restless sleep 16-20 years after school leaving (coefficients in the probability of reporting restless sleep regressions are less precise). The improvements in restless sleep due to leaving school in an economic downturn dissipate after 25 years in the labor market (the coefficient estimates on the indicator for 26-37 years potential experience carry negative signs, but the magnitude of the effect declines and becomes statistically indistinguishable from zero).

Table 5: Effect of economic conditions faced at school leaving on sleep quality: NLSY79 2SLS model.

\begin{tabular}{lll}
\hline Outcome & Restless sleep (0-3) & Frequent restless sleep \\
\hline Men &
\end{tabular}




$\begin{array}{lll}\text { Sample mean/proportion } & 0.6477 & 0.1688 \\ \text { 6-10 years potential experience } & 0.0152 & 0.0138^{* *} \\ \text { 11-15 years potential experience } & (0.0190) & (0.0066) \\ & -0.0092 & -0.0012 \\ \text { 16-20 years potential experience } & (0.0130) & (0.0047) \\ & -0.0226^{*} & -0.0037 \\ \text { 21-25 years potential experience } & (0.0122) & (0.0044) \\ & -0.0295^{* *} & -0.0076^{*} \\ \text { 26-37 years potential experience } & (0.0116) & (0.0041) \\ & -0.0207 & -0.0057 \\ \text { Observations } & (0.0155) & (0.0052) \\ \text { Clusters } & 13,479 & 13,479 \\ \text { Women } & 48 & 48 \\ \text { Sample mean/proportion } & 0.8167 & 0.2263 \\ \text { 6-10years potential experience } & -0.0368 & -0.0104 \\ & (0.0296) & (0.0098) \\ \text { 11-15 years potential experience } & -0.0279 & -0.0120^{*} \\ & (0.0219) & (0.0072) \\ \text { 16-20 years potential experience } & -0.0469^{* *} & -0.0160^{* *} \\ & (0.0213) & (0.0071) \\ \text { 21-25 years potential experience } & -0.0306^{*} & -0.0093 \\ \text { 26-37 years potential experience } & (0.0176) & (0.0066) \\ & -0.0037 & 0.0012 \\ \text { Observations } & (0.0194) & (0.0083) \\ \text { Clusters } & 14,124 & 14,124 \\ \end{array}$

***:***; and ${ }^{*}=$ statistically different from zero at the $1 \% ; 5 \%$; and $10 \%$ level, respectively.

Notes: All models estimated with 2SLS and control for potential experience, demographics, on time school-leaving state fixed effects, and on time school-leaving year fixed effects. NLSY79 sample weights applied. Standard errors reported in parentheses and clustered around the on time school-leaving state.

Turning to women, we see that leaving school in an economic downturn has beneficial effects for women but these effects are not immediately observable (i. e. they are not statistically distinguishable in the initial period we measure: 6-10 years after school leaving). Instead, 11-20 years after school leaving those women who leave school in an economic downturn are less likely to experience restless sleep. For example, a 1 percentage point increase in the school-leaving state unemployment rate leads to a 1.2 percentage point $(5.3 \%)$ and a 1.6 percentage point $(7.1 \%)$ reduction in the probability of reporting frequent restless sleep after 11-15 and 16-20 years after school leaving. After 20 years in the labor market, the coefficient estimates are no longer statistically different from zero in the probability of reporting frequent sleep problems regression, although the estimates on the indicator variables for these more distal periods do carry negative signs. The coefficient estimates in the sleep quality score are broadly similar.

\subsection{Heterogeneity}

Economic theory and previous research suggest differences in the labor market and marriage market penalties attributable to leaving school in an economic downturn by worker characteristics. In particular, the literature highlights the importance of considering heterogeneity by worker skill level (Genda, Kondo, and Ohta 2010), ability (Mansour 2009), and race and ethnicity (Kondo 2015). ${ }^{25}$ We next explore heterogeneity in sleep quality effects across these worker characteristics. More specifically, we stratify our sample by skill as defined by education at school leaving (less than a 4-year college degree vs. a 4-year college degree or more), ${ }^{26}$ ability as defined by the age adjusted AFQT score (the top tercile vs. the second and first tercile of the empirical distribution), and race and ethnicity (White vs. non-White). We report results generated in 2SLS regressions for brevity.

As noted in Section 3.5, one may be concerned that our instruments are more accurately measured for those respondents who leave school with a standard educational credential (i. e. high school diploma or 4-year college degree) than for those who leave school with a nonstandard degree or who drop out (e.g. a 2-year college degree, those who drop out before completing a credential). Moreover, it is plausible that these groups are differentially likely to violate the exclusion restriction. We therefore estimate separate 2SLS regressions for the sample of standard credentialed students (high school diploma and 4-year college degree at school leaving) and nonstandard credentialed students (all other students).

Before preceding to our analysis of heterogeneity, we report first stage regressions and associated $F$ statistics for each of the subsamples described above. Results are reported in Table 6. Overall, our analysis of the first 
stage regressions across our subsamples suggests that the IV is a strong predictor of our treatment variable. More specifically, the $F$ statistic ranges from a low of 22 (high ability women as defined by the age adjusted AFQT score) to a high of 62 (low ability women as defined by the age adjusted AFQT score). Moreover, the coefficient estimates on the instrument (the on time school-leaving state unemployment rate) are all positive and statistically different from zero at the $1 \%$ level. One exception to this pattern of results is the high-skill men and women samples as defined by education at school leaving. The $F$ statistics on the instrument in these samples are 18 (high-skill men) and 5 (high-skill women). We note that the IV is weak in these subsamples as a limitation of the study and encourage readers to interpret findings generated in the subsamples of high-skill men and women with some caution.

Table 6: Heterogeneity across subgroups in first stage OLS regressions: NLSY79.

\begin{tabular}{|c|c|c|}
\hline Sample & Men & Women \\
\hline \multicolumn{3}{|l|}{ Skill level heterogeneity } \\
\hline Sample mean & 7.6637 & 7.9334 \\
\hline \multirow[t]{2}{*}{ High skill } & $0.1737^{* * *}$ & $0.1064^{* * *}$ \\
\hline & $(0.0407)$ & $(0.0461)$ \\
\hline \multicolumn{3}{|l|}{$\begin{array}{l}\text { school-leaving state unemployment } \\
\text { rate ( } p \text { value) }\end{array}$} \\
\hline Observations & 2,167 & 2,342 \\
\hline Clusters & 46 & 46 \\
\hline Sample mean & 7.3789 & 7.3481 \\
\hline \multirow[t]{2}{*}{ Low skill } & $0.2911^{* * *}$ & $0.2972^{* * *}$ \\
\hline & $(0.0392)$ & $(0.0411)$ \\
\hline \multicolumn{3}{|l|}{$\begin{array}{l}\text { school-leaving state unemployment } \\
\text { rate ( } p \text { value) }\end{array}$} \\
\hline Observations & 11,312 & 11,782 \\
\hline Clusters & 49 & 44 \\
\hline \multicolumn{3}{|l|}{ Ability heterogeneity } \\
\hline Sample mean & 7.4180 & 7.4870 \\
\hline \multirow[t]{2}{*}{ 1st AFQT tercile } & $0.2644^{* * *}$ & $0.2250^{* * *}$ \\
\hline & $(0.0423)$ & $(0.0477)$ \\
\hline $\begin{array}{l}F \text { statistic on the on time } \\
\text { school-leaving state unemployment } \\
\text { rate ( } p \text { value) }\end{array}$ & $39.08(0.0000)$ & $22.20(0.0000)$ \\
\hline Observations & 4,699 & 4,562 \\
\hline Clusters & 49 & 44 \\
\hline Sample mean & 7.4572 & 7.4512 \\
\hline \multirow[t]{2}{*}{ 2nd and 3rd AFQT tercile } & $0.3076^{* * *}$ & $0.3196^{* * *}$ \\
\hline & $(0.0403)$ & $(0.0407)$ \\
\hline $\begin{array}{l}F \text { statistic on the on time } \\
\text { school-leaving state unemployment } \\
\text { rate ( } p \text { value) }\end{array}$ & $58.18(0.0000)$ & $61.63(0.0000)$ \\
\hline Observations & 8,780 & 9,562 \\
\hline Clusters & 48 & 44 \\
\hline \multicolumn{3}{|l|}{ Race and ethnicity heterogeneity } \\
\hline Sample mean & 7.4723 & 7.5116 \\
\hline \multirow[t]{2}{*}{ White } & $0.2814^{* * *}$ & $0.2767^{* * *}$ \\
\hline & $(0.0379)$ & $(0.0486)$ \\
\hline $\begin{array}{l}F \text { statistic on the on time } \\
\text { school-leaving state unemployment } \\
\text { rate ( } p \text { value) }\end{array}$ & $55.16(0.0000)$ & $32.39(0.0000)$ \\
\hline Observations & 6,973 & 7,320 \\
\hline Clusters & 49 & 44 \\
\hline Sample mean & 7.3048 & 7.2826 \\
\hline \multirow[t]{2}{*}{ Nonwhite } & $0.2493^{* * *}$ & $0.2926^{* * *}$ \\
\hline & $(0.0365)$ & $(0.0392)$ \\
\hline $\begin{array}{l}F \text { statistic on the on time } \\
\text { school-leaving state unemployment } \\
\text { rate ( } p \text { value) }\end{array}$ & $46.72(0.0000)$ & $55.83(0.0000)$ \\
\hline Observations & 6,506 & 6,804 \\
\hline Clusters & 43 & 43 \\
\hline
\end{tabular}




\begin{tabular}{lll}
$\begin{array}{l}\text { Credentialed heterogeneity } \\
\text { Sample mean }\end{array}$ & 7.5034 & 7.4953 \\
Standard credential & $0.3015^{* * *}$ & $0.2862^{* * *}$ \\
& $(0.0417)$ & $(0.0451)$ \\
$\begin{array}{l}\text { F statistic on the on time } \\
\text { school-leaving state unemployment }\end{array}$ & $52.40(0.0000)$ & $40.21(0.0000)$ \\
rate $(p$ value) & & \\
$\begin{array}{l}\text { Observations } \\
\text { Clusters }\end{array}$ & 9,562 & 9,739 \\
Sample mean & 50 & 46 \\
Nonstandard credential & 7.2590 & 7.3974 \\
& $0.2366^{* * *}$ & $0.2700^{* * *}$ \\
$\begin{array}{l}\text { F statistic on the on time } \\
\text { school-leaving state unemployment } \\
\text { rate }(p \text { value })\end{array}$ & $(0.0345)$ & $(0.0548)$ \\
Observations & $46.92(0.0000)$ & $24.31(0.0000)$ \\
Clusters & & \\
\hline
\end{tabular}

$* * * * * *$; and $*$ statistically different from zero at the $1 \% ; 5 \%$; and $10 \%$ level, respectively.

Notes: The outcome in all regressions in the school-leaving state unemployment rate. All models estimated with OLS and control for potential experience, demographics, on time school-leaving state fixed effects, and on time school-leaving year fixed effects. NLSY79 sample weights applied. Standard errors reported in parentheses and clustered around the on time school-leaving state.

Table 7-Table 14 report heterogeneity in the effects of leaving school in an economic downturn on sleep quality by skill, ability, race/ethnicity, and educational credentials, respectively.

Table 7: Heterogeneity by skill level in the effect of economic conditions faced at school leaving on sleep quality among men: NLSY79 2SLS model.

\begin{tabular}{|c|c|c|}
\hline Outcome & Restless sleep (0-3) & Frequent restless sleep \\
\hline \multicolumn{3}{|l|}{ High-skill men } \\
\hline Sample mean/proportion & 0.5418 & 0.1218 \\
\hline \multirow{2}{*}{$6-10$ years potential experience } & 0.0554 & $0.0390^{* *}$ \\
\hline & $(0.0430)$ & $(0.0187)$ \\
\hline \multirow[t]{2}{*}{$11-15$ years potential experience } & 0.0323 & 0.0215 \\
\hline & $(0.0381)$ & $(0.0143)$ \\
\hline \multirow[t]{2}{*}{ 16-20 years potential experience } & 0.0215 & 0.0183 \\
\hline & $(0.0403)$ & $(0.0148)$ \\
\hline \multirow[t]{2}{*}{ 21-25 years potential experience } & -0.0154 & 0.0114 \\
\hline & $(0.0397)$ & $(0.0165)$ \\
\hline \multirow[t]{2}{*}{ 26-37 years potential experience } & 0.0245 & 0.0125 \\
\hline & $(0.0502)$ & $(0.0173)$ \\
\hline Observations & 2,167 & 2,167 \\
\hline Clusters & 41 & 41 \\
\hline \multicolumn{3}{|l|}{ Low-skill men } \\
\hline Sample mean/proportion & 0.7158 & 0.1973 \\
\hline \multirow[t]{2}{*}{$6-10$ years potential experience } & 0.4674 & 0.1603 \\
\hline & $(0.5516)$ & $(0.1963)$ \\
\hline \multirow[t]{2}{*}{$11-15$ years potential experience } & 0.4526 & 0.1495 \\
\hline & $(0.5947)$ & $(0.2202)$ \\
\hline \multirow[t]{2}{*}{ 16-20 years potential experience } & 0.0631 & 0.0213 \\
\hline & $(0.4584)$ & $(0.1543)$ \\
\hline \multirow[t]{2}{*}{ 21-25 years potential experience } & 0.1175 & 0.0389 \\
\hline & $(0.3113)$ & $(0.1086)$ \\
\hline \multirow[t]{2}{*}{ 26-37 years potential experience } & 0.1695 & 0.0572 \\
\hline & $(0.2085)$ & $(0.0798)$ \\
\hline Observations & 11,312 & 11,312 \\
\hline Clusters & 48 & 48 \\
\hline
\end{tabular}

***; ***; and * statistically different from zero at the $1 \% ; 5 \%$; and $10 \%$ level, respectively.

Notes: All models estimated with 2SLS and control for potential experience, demographics, on time school-leaving state fixed effects, and on time school-leaving year fixed effects. NLSY79 sample weights applied. Standard errors reported in parentheses and clustered around the on time school-leaving state. 
Table 8: Heterogeneity by skill level in the effect of economic conditions faced at school leaving on sleep quality among women: NLSY79 2SLS model.

\begin{tabular}{|c|c|c|}
\hline Outcome & Restless sleep (0-3) & Frequent restless sleep \\
\hline \multicolumn{3}{|l|}{ High-skill women } \\
\hline Sample mean/proportion & 0.7120 & 0.1761 \\
\hline \multirow{2}{*}{$6-10$ years potential experience } & 0.0204 & 0.0428 \\
\hline & $(0.0989)$ & $(0.0338)$ \\
\hline \multirow[t]{2}{*}{$11-15$ years potential experience } & 0.0100 & 0.0330 \\
\hline & $(0.0844)$ & $(0.0297)$ \\
\hline \multirow[t]{2}{*}{ 16-20 years potential experience } & 0.0045 & 0.0348 \\
\hline & $(0.0918)$ & $(0.0335)$ \\
\hline \multirow[t]{2}{*}{$21-25$ years potential experience } & -0.0434 & -0.0064 \\
\hline & $(0.1072)$ & $(0.0449)$ \\
\hline \multirow{2}{*}{$26-37$ years potential experience } & 0.0173 & 0.0346 \\
\hline & $(0.0835)$ & $(0.0309)$ \\
\hline Observations & 2,342 & 2,342 \\
\hline Clusters & 41 & 41 \\
\hline \multicolumn{3}{|l|}{ Low-skill women } \\
\hline Sample mean/proportion & 0.8987 & 0.2535 \\
\hline \multirow{2}{*}{$6-10$ years potential experience } & $-0.2544^{* * *}$ & $-0.0703^{* * *}$ \\
\hline & $(0.0549)$ & $(0.0159)$ \\
\hline \multirow[t]{2}{*}{$11-15$ years potential experience } & -0.0465 & -0.0188 \\
\hline & $(0.0495)$ & $(0.0142)$ \\
\hline \multirow[t]{2}{*}{ 16-20 years potential experience } & -0.0166 & -0.0096 \\
\hline & $(0.0520)$ & $(0.0151)$ \\
\hline \multirow[t]{2}{*}{ 21-25 years potential experience } & 0.0045 & -0.0024 \\
\hline & $(0.0410)$ & $(0.0114)$ \\
\hline \multirow[t]{2}{*}{ 26-37 years potential experience } & 0.0564 & 0.0144 \\
\hline & $(0.0463)$ & $(0.0141)$ \\
\hline Observations & 11,782 & 11,782 \\
\hline Clusters & 48 & 48 \\
\hline
\end{tabular}

$*_{* * * * * *}^{* *}$; and ${ }^{*}=$ statistically different from zero at the $1 \% ; 5 \%$; and $10 \%$ level, respectively.

Notes: All models estimated with 2SLS and control for potential experience, demographics, on time school-leaving state fixed effects, and on time school-leaving year fixed effects. NLSY79 sample weights applied. Standard errors reported in parentheses and clustered around the on time school-leaving state.

In terms of worker skill, we find that the sleep quality effects that we observe in the full sample of men are only observable in the high-skill sample of men: leaving school in an economic downturn leads to an increase in restless sleep early in the career, but not after 10 years. Interestingly, we do not observe the reduction in restless sleep later in the career that we observed in the full sample of men. Indeed, while the coefficient estimates are imprecise, they do generally carry a positive sign and suggest that higher skill men who leave school in an economic downturn may persistently experience restless sleep. While the estimates are again imprecise, we also find evidence that lower skill men who leave school in an economic downturn have more restless sleep, and this effect persists.

Among higher skill women, we find some evidence of the U-shaped relationship between leaving school in an economic downturn and restless sleep that we observed in the full sample, but all coefficient estimates are imprecise. Lower skill women who leave school when the state unemployment rate is high experience improved sleep quality, but this effect is only precisely estimated 10 years after school leaving. In subsequent periods, the estimated effects are no longer different from zero (in the most distal period, coefficient estimates are positive).

We next stratify the sample based on ability as proxied by the age adjusted AFQT score (Table 9 and Table 10). Although higher ability men (top tercile of the age adjusted AFQT distribution) appear to experience an inverted U relationship between economic conditions at school leaving and restless sleep comparable to the full sample (i.e. an initial increase in low-quality sleep early in the career followed by declines in low-quality sleep later in the career), the coefficient estimates are generally imprecise. While the findings for lower ability men do not reveal many statistically significant coefficient estimates, overall lower ability men who leave school in an economic downturn appear less likely to experience restless sleep.

Table 9: Heterogeneity by ability level in the effect of economic conditions faced at school leaving on sleep quality among men: NLSY79 2SLS model.

\begin{tabular}{lll}
\hline Outcome & Restless sleep (0-3) & Frequent restless sleep \\
\hline Men in the 1st AFQT tercile &
\end{tabular}

Men in the 1st AFQT tercile 


$\begin{array}{lll}\text { Sample mean/proportion } & 0.6197 & 0.1532 \\ \text { 6-10 years potential experience } & 0.0040 & 0.0105 \\ & (0.0278) & (0.0111) \\ \text { 11-15 years potential experience } & -0.0180 & -0.0018 \\ & (0.0226) & (0.0094) \\ \text { 16-20 years potential experience } & -0.0342 & -0.0076 \\ & (0.0225) & (0.0083) \\ \text { 21-25 years potential experience } & -0.0423^{*} & -0.0105 \\ & (0.0224) & (0.0088) \\ \text { 26-37 years potential experience } & -0.0273 & -0.0097 \\ & (0.0241) & (0.0084) \\ \text { Observations } & 4,699 & 4,699 \\ \text { Clusters } & 47 & 47 \\ \text { Men in the 2nd and 3rd AFQT tercile } & & \\ \text { Sample mean/proportion } & 0.7312 & 0.2061 \\ \text { 6-10 years potential experience } & -0.1202 & -0.3501 \\ & (0.3078) & (0.4111) \\ \text { 11-15 years potential experience } & 0.0303 & 0.0143 \\ & (0.0298) & (0.0147) \\ \text { 16-20 years potential experience } & 0.0001 & -0.0018 \\ & (0.0166) & (0.0106) \\ \text { 21-25 years potential experience } & -0.0131 & -0.0067 \\ & (0.0174) & (0.0123) \\ \text { 26-37 years potential experience } & -0.0208 & -0.0074 \\ \text { Observations } & (0.0145) & (0.0078) \\ \text { Clusters } & 8,780 & 8,780 \\ \end{array}$

***; ***; and * statistically different from zero at the $1 \% ; 5 \%$; and $10 \%$ level, respectively.

Notes: All models estimated with $2 \mathrm{SLS}$ and control for potential experience, demographics, on time school-leaving state fixed effects, and on time school-leaving year fixed effects. NLSY79 sample weights applied. Standard errors reported in parentheses and clustered around the on time school-leaving state.

Table 10: Heterogeneity by ability level in the effect of economic conditions faced at school leaving on sleep quality among women: NLSY79 2SLS model.

\begin{tabular}{|c|c|c|}
\hline Outcome & Restless sleep (0-3) & Frequent restless sleep \\
\hline \multicolumn{3}{|l|}{ Women in the 1st AFQT tercile } \\
\hline Sample mean/proportion & 0.7719 & 0.2001 \\
\hline \multirow[t]{2}{*}{ 6-10 years potential experience } & $-0.0644^{*}$ & -0.0170 \\
\hline & $(0.0379)$ & $(0.0151)$ \\
\hline \multirow[t]{2}{*}{ 11-15 years potential experience } & -0.0346 & -0.0123 \\
\hline & $(0.0292)$ & $(0.0117)$ \\
\hline \multirow[t]{2}{*}{ 16-20 years potential experience } & $-0.0641^{* *}$ & $-0.0239^{* *}$ \\
\hline & $(0.0284)$ & $(0.0116)$ \\
\hline \multirow[t]{2}{*}{ 21-25 years potential experience } & -0.0395 & -0.0149 \\
\hline & $(0.0263)$ & $(0.0116)$ \\
\hline \multirow[t]{2}{*}{ 26-37 years potential experience } & -0.0111 & -0.0095 \\
\hline & $(0.0267)$ & $(0.0118)$ \\
\hline Observations & 4,562 & 4,562 \\
\hline Clusters & 45 & 45 \\
\hline \multicolumn{3}{|c|}{ Women in the 2 nd and $3 r d$ AFQT tercile } \\
\hline Sample mean/proportion & 0.9304 & 0.2673 \\
\hline \multirow[t]{2}{*}{ 6-10 years potential experience } & -0.0182 & -0.0090 \\
\hline & $(0.0250)$ & $(0.0092)$ \\
\hline \multirow[t]{2}{*}{$11-15$ years potential experience } & -0.0298 & $-0.0148^{*}$ \\
\hline & $(0.0224)$ & $(0.0090)$ \\
\hline \multirow[t]{2}{*}{ 16-20 years potential experience } & -0.0368 & -0.0118 \\
\hline & $(0.0224)$ & $(0.0085)$ \\
\hline \multirow[t]{2}{*}{ 21-25 years potential experience } & -0.0289 & -0.0066 \\
\hline & $(0.0188)$ & $(0.0070)$ \\
\hline \multirow[t]{2}{*}{ 26-37 years potential experience } & -0.0004 & 0.0105 \\
\hline & $(0.0257)$ & $(0.0098)$ \\
\hline Observations & 9,562 & 9,562 \\
\hline
\end{tabular}


${ }^{* * * * * * *}$; and ${ }^{*}=$ statistically different from zero at the $1 \% ; 5 \%$; and $10 \%$ level, respectively.

Notes: All models estimated with 2SLS and control for potential experience, demographics, on time school leaving state fixed effects, and on time school leaving year fixed effects. NLSY79 sample weights applied. Standard errors reported in parentheses and clustered around the on time school leaving state.

Among women, we find that those with higher ability experience better sleep quality 20 years after school leaving (although the coefficient estimates are less precise at 6-10 years after school leaving than they are at midcareer). We find some evidence that lower ability women who leave school in an economic downturn may experience improvements in sleep quality, but only one coefficient estimate (the coefficient on the indicator variable for 11-15 years after school leaving) is statistically distinguishable from zero.

We next split the sample by race and ethnicity and estimate our regression models (Table 11 and Table 12). Among white men, we observe the initial increase in low-quality sleep (through the first 10 years after school leaving), then a reduction in low-quality sleep that dissipates after 25 years in the labor market (although coefficients retain a negative sign over the period for which we can track men) among those who leave school when the state unemployment rate is high. We observe a similar inverted U-shape relationship between the school-leaving state unemployment rate and sleep quality among nonwhite men, but the coefficient estimates are generally not statistically different from zero. Among women, both white and nonwhite, we find that those who leave school when the state unemployment rate is high experience better sleep quality, but the coefficients are only statistically different from zero for white women and at midcareer (16-20 years after school leaving).

Table 11: Heterogeneity by race and ethnicity in the effect of economic conditions faced at school leaving on sleep quality among men: NLSY79 2SLS model.

\begin{tabular}{|c|c|c|}
\hline Outcome & Restless sleep (0-3) & Frequent restless sleep \\
\hline \multicolumn{3}{|l|}{ White men } \\
\hline Sample mean/proportion & 0.6825 & 0.1817 \\
\hline \multirow{2}{*}{$6-10$ years potential experience } & 0.0167 & $0.0163^{*}$ \\
\hline & $(0.0229)$ & $(0.0080)$ \\
\hline \multirow[t]{2}{*}{$11-15$ years potential experience } & -0.0162 & -0.0030 \\
\hline & $(0.0150)$ & $(0.0056)$ \\
\hline \multirow[t]{2}{*}{ 16-20 years potential experience } & -0.0244 & -0.0034 \\
\hline & $(0.0150)$ & $(0.0055)$ \\
\hline \multirow{2}{*}{$21-25$ years potential experience } & $-0.0335^{* * *}$ & $-0.0089^{* *}$ \\
\hline & $(0.0127)$ & $(0.0044)$ \\
\hline \multirow[t]{2}{*}{ 26-37 years potential experience } & -0.0232 & -0.0070 \\
\hline & $(0.0178)$ & $(0.0059)$ \\
\hline Observations & 6,973 & 6,973 \\
\hline Clusters & 47 & 47 \\
\hline \multicolumn{3}{|l|}{ Nonwhite men } \\
\hline Sample mean/proportion & 0.6657 & 0.1799 \\
\hline \multirow{2}{*}{$6-10$ years potential experience } & 0.0350 & 0.0098 \\
\hline & $(0.0231)$ & $(0.0129)$ \\
\hline \multirow[t]{2}{*}{$11-15$ years potential experience } & $0.0414^{*}$ & 0.0106 \\
\hline & $(0.0243)$ & $(0.0093)$ \\
\hline \multirow[t]{2}{*}{ 16-20 years potential experience } & -0.0029 & -0.0050 \\
\hline & $(0.0201)$ & $(0.0067)$ \\
\hline \multirow[t]{2}{*}{ 21-25 years potential experience } & -0.0021 & -0.0017 \\
\hline & $(0.0211)$ & $(0.0077)$ \\
\hline \multirow[t]{2}{*}{ 26-37 years potential experience } & -0.0059 & -0.0020 \\
\hline & $(0.0251)$ & $(0.0087)$ \\
\hline Observations & 6,506 & 6,506 \\
\hline Clusters & 46 & 46 \\
\hline
\end{tabular}

***; ${ }^{* * *}$; and ${ }^{*}=$ statistically different from zero at the $1 \% ; 5 \%$; and $10 \%$ level, respectively.

Notes: All models estimated with 2SLS and control for potential experience, demographics, on time school leaving state fixed effects, and on time school leaving year fixed effects. NLSY79 sample weights applied. Standard errors reported in parentheses and clustered around the on time school leaving state.

Table 12: Heterogeneity by race and ethnicity in the effect of economic conditions faced at school leaving on sleep quality among women: NLSY79 2SLS model.

\begin{tabular}{lll}
\hline Outcome & Restless sleep (0-3) & Frequent restless sleep
\end{tabular}


White women

Sample mean/proportion

6-10 years potential experience

0.8583

$-0.0350$

$(0.0303)$

11-15 years potential experience

16-20 years potential experience

21-25 years potential experience

26-37 years potential experience

Observations

Clusters

Nonwhite women

Sample mean/proportion

6-10 years potential experience

11-15 years potential experience

16-20 years potential experience

21-25 years potential experience

26-37 years potential experience

Observations

Clusters
$-0.0230$

$(0.0214)$

$-0.0444^{* *}$

(0.0209)

$-0.0251$

(0.0182)

0.0024

(0.0209)

7,320

45

0.8712

$-0.0322$

(0.0366)

$-0.0361$

(0.0301)

$-0.0419$

(0.0325)

$-0.0429$

(0.0280)

$-0.0174$

(0.0354)

6,804

44
0.2365
$-0.0086$
(0.0099)
$-0.0095$
(0.0067)
$-0.0144^{* *}$
(0.0067)
$-0.0065$
(0.0068)
0.0039
(0.0087)
7,320
45
0.2430
$-0.0135$
(0.0151)
$-0.0179$
(0.0122)
$-0.0178$
(0.0130)
$-0.0166$
(0.0110)
$-0.0059$
(0.0134)
6,804
44

***; $;{ }^{* * *}$; and ${ }^{*}=$ statistically different from zero at the $1 \% ; 5 \%$; and $10 \%$ level, respectively.

Notes: All models estimated with 2SLS and control for potential experience, demographics, on time school leaving state fixed effects, and on time school leaving year fixed effects. NLSY79 sample weights applied. Standard errors reported in parentheses and clustered around the on time school leaving state.

As noted earlier in the manuscript, a concern with our instruments is that they are potentially more accurately measured for those individuals who leave school with a standard educational credential (i. e. a high school diploma or a 4-year college degree) than for other individuals. Moreover, one may be concerned that those individuals who leave school with and without a standard educational credential (as we have defined them) may be differentially responsive to economic conditions in terms of remaining in school, which may in turn lead to differential risk for violation of the exclusion restriction between these two groups.

To explore these possibilities, we estimate separate regressions for those individuals who leave school with a standard educational credential (i. e. a high school diploma or a 4-year college degree) and all other individuals in our sample. Results are reported in Table 13 and Table 14. Among credentialed men, we observe an inverted $U$ relationship between the school-leaving state unemployment rate and restless sleep. However, the estimated coefficients are often imprecise. These findings are comparable to the full sample and the samples of higher skill and ability men. In the nonstandard credential sample, we find no statistically significant evidence that leaving school in an economic downturn impacts sleep quality. The coefficient estimates are generally negative, which suggests that noncredentialed men who leave school in an economic downturn experience higher quality sleep, but the coefficients are imprecise. In the female sample, we observe evidence that women, regardless of their educational credential at school leaving, experience better quality sleep, but the coefficients are generally imprecise. $^{27}$

Table 13: Heterogeneity by educational credentials in the effect of economic conditions faced at school leaving on sleep quality among men: NLSY79 2SLS model.

\begin{tabular}{lll}
\hline Outcome & Restless sleep (0-3) & Frequent restless sleep \\
\hline Standard credential men & & \\
Sample mean/proportion & 0.6572 & 0.1740 \\
6-10 years potential experience & 0.0381 & $0.0220^{* *}$ \\
& $(0.0236)$ & $(0.0095)$ \\
11-15 years potential experience & 0.0074 & 0.0041 \\
& $(0.0202)$ & $(0.0078)$ \\
16-20 years potential experience & -0.0067 & 0.0018 \\
& $(0.0190)$ & $(0.0069)$
\end{tabular}




$\begin{array}{lll}\text { 21-25 years potential experience } & -0.0163 & -0.0042 \\ & (0.0174) & (0.0065) \\ \text { 26-37 years potential experience } & -0.0151 & -0.0044 \\ & (0.0215) & (0.0078) \\ \text { Observations } & 9,562 & 9,562 \\ \text { Clusters } & 47 & 47 \\ \text { Nonstandard credential men } & & \\ \text { Sample mean/proportion } & 0.7401 & 0.2018 \\ \text { 6-10years potential experience } & -0.0206 & -0.0026 \\ & (0.0443) & (0.0146) \\ \text { 11-15years potential experience } & -0.0222 & -0.0075 \\ & (0.0424) & (0.0166) \\ \text { 16-20 years potential experience } & -0.0436 & -0.0158 \\ & (0.0347) & (0.0131) \\ \text { 21-25 years potential experience } & -0.0272 & -0.0053 \\ & (0.0332) & (0.0124) \\ \text { 26-37 years potential experience } & -0.0049 & 0.0014 \\ & (0.0325) & (0.0124) \\ \text { Observations } & 3,917 & 3,917 \\ \text { Clusters } & 43 & 43\end{array}$

$* * * * * ;$ and ${ }^{*}=$ statistically different from zero at the $1 \% ; 5 \%$; and $10 \%$ level, respectively.

Notes: All models estimated with 2 SLS and control for potential experience, demographics, on time school leaving state fixed effects, and on time school leaving year fixed effects. NLSY79 sample weights applied. Standard errors reported in parentheses and clustered around the on time school leaving state.

Table 14: Heterogeneity by educational credentials in the effect of economic conditions faced at school leaving on sleep quality among women: NLSY79 2SLS model.

\begin{tabular}{|c|c|c|}
\hline Outcome & Restless sleep (0-3) & Frequent restless sleep \\
\hline \multicolumn{3}{|l|}{ Standard credential women } \\
\hline Sample mean/proportion & 0.8440 & 0.2333 \\
\hline \multirow[t]{2}{*}{$6-10$ years potential experience } & -0.0468 & -0.0153 \\
\hline & $(0.0388)$ & $(0.0136)$ \\
\hline \multirow[t]{2}{*}{$11-15$ years potential experience } & -0.0357 & -0.0153 \\
\hline & $(0.0269)$ & $(0.0101)$ \\
\hline \multirow[t]{2}{*}{ 16-20 years potential experience } & $-0.0512^{*}$ & -0.0182 \\
\hline & $(0.0304)$ & $(0.0114)$ \\
\hline \multirow[t]{2}{*}{$21-25$ years potential experience } & -0.0383 & -0.0116 \\
\hline & $(0.0255)$ & $(0.0102)$ \\
\hline \multirow[t]{2}{*}{ 26-37 years potential experience } & -0.0135 & -0.0008 \\
\hline & $(0.0286)$ & $(0.0124)$ \\
\hline Observations & 9,739 & 9,739 \\
\hline Clusters & 48 & 48 \\
\hline \multicolumn{3}{|l|}{ Nonstandard credential women } \\
\hline Sample mean/proportion & 0.9021 & 0.2487 \\
\hline \multirow[t]{2}{*}{$6-10$ years potential experience } & -0.0224 & -0.0023 \\
\hline & $(0.0281)$ & $(0.0124)$ \\
\hline \multirow[t]{2}{*}{$11-15$ years potential experience } & -0.0220 & -0.0085 \\
\hline & $(0.0315)$ & $(0.0131)$ \\
\hline \multirow[t]{2}{*}{ 16-20 years potential experience } & $-0.0477^{*}$ & -0.0135 \\
\hline & $(0.0270)$ & $(0.0125)$ \\
\hline \multirow[t]{2}{*}{$21-25$ years potential experience } & -0.0199 & -0.0060 \\
\hline & $(0.0301)$ & $(0.0137)$ \\
\hline \multirow[t]{2}{*}{ 26-37 years potential experience } & 0.0150 & 0.0049 \\
\hline & $(0.0399)$ & $(0.0168)$ \\
\hline Observations & 4,385 & 4,385 \\
\hline Clusters & 43 & 43 \\
\hline
\end{tabular}

*:**:**; and * = statistically different from zero at the $1 \% ; 5 \%$; and $10 \%$ level, respectively.

Notes: All models estimated with 2 SLS and control for potential experience, demographics, on time school leaving state fixed effects, and on time school leaving year fixed effects. NLSY79 sample weights applied. Standard errors reported in parentheses and clustered around the on time school leaving state. 


\subsection{Sleep Quantity}

We next examine the impact of leaving school in an economic down turn on sleep quantity. To examine sleep quantity, we rely on information collected in the NLSY79 Age 50 and Over Health Module. This module was collected in 2008, 2010, and 2012 when respondents are approximately 50 years of age. A limitation of using these data is that not all respondents have completed the Module because the final round of the Module was collected in 2014 and will not be available to researchers until late $2016 .{ }^{28}$ Nonetheless, using information collected in the Module allows us to provide some evidence on the long run impacts of leaving school in an economic downturn on sleep quantity. We have sleep quantity data on 2,361 unique men and 2,565 unique women.

We rely on up to one observation per respondent, and we have data on only three quarters of the NLSY79 sample. To account for a smaller sample, we estimate a variant of eq. 1 to study sleep quantity. Specifically, we do not allow for interactions between the school-leaving state and potential experience as we believe this asks too much of the data (Maclean 2013). This model assumes that the effect of leaving school in an economic downturn on sleep quantity is constant for members of this sample, we note this as a limitation of the study. We report results generated in both OLS and 2SLS models.

Table 15 presents OLS results on sleep quantity for the full sample of men and women. Although the coefficient estimates are not statistically different from zero, we find that men who leave school when the state unemployment rate is high are less likely to sleep less than $5 \mathrm{~h}$ per night and less likely to sleep 5 to less than $6 \mathrm{~h}$ per night. We observe that a 1 percentage point increase in the school-leaving state unemployment rate leads to a $12.4 \%$ increase in the probability of sleeping 6 to less than $7 \mathrm{~h}$ per night and a $9.2 \%$ decrease in the probability of sleeping 7 to less than $8 \mathrm{~h}$ per night, and these coefficient estimates are statistically different from zero. The coefficient estimates in the regressions of the propensity to sleep 8 to less than $9 \mathrm{~h}$ and 9 or more hours suggest that a 1 percentage point increase in the school-leaving state unemployment rate reduces the former propensity by $2.1 \%$ and increases the latter propensity by $8.5 \%$.

Table 15: Effect of economic conditions faced at school leaving on sleep quantity outcomes: NLSY79 50 and Over Health Module OLS model.

\begin{tabular}{|c|c|c|c|c|c|c|}
\hline Outcome & Sleep $<5 \mathrm{~h}$ & Sleep 5-<6h & Sleep $6-<7 \mathrm{~h}$ & Sleep 7-<8h & Sleep $8-<9 h$ & Sleep 9+ h \\
\hline \multicolumn{7}{|l|}{ Men } \\
\hline $\begin{array}{l}\text { Sample } \\
\text { proportion }\end{array}$ & 0.0604 & 0.1039 & 0.2751 & 0.3243 & 0.2056 & 0.0306 \\
\hline School & -0.0012 & -0.0015 & $0.0341^{* *}$ & $-0.0297^{* *}$ & -0.0043 & 0.0026 \\
\hline $\begin{array}{l}\text { leaving } \\
\text { state UE rate }\end{array}$ & $(0.0036)$ & $(0.0081)$ & $(0.0131)$ & $(0.0115)$ & $(0.0086)$ & $(0.0031)$ \\
\hline Clusters & 2,361 & 2,361 & 2,361 & 2,361 & 2,361 & 2,361 \\
\hline $\begin{array}{l}\text { Observations } \\
\text { Women }\end{array}$ & 49 & 49 & 49 & 49 & 49 & 49 \\
\hline $\begin{array}{l}\text { Sample } \\
\text { proportion }\end{array}$ & 0.054 & 0.0964 & 0.2581 & 0.3123 & 0.2352 & 0.0439 \\
\hline $\begin{array}{l}\text { School } \\
\text { leaving }\end{array}$ & $-0.0177^{* * *}$ & 0.0006 & 0.0058 & 0.0028 & 0.0045 & 0.0040 \\
\hline state UE rate & $(0.0062)$ & $(0.0073)$ & $(0.0078)$ & $(0.0087)$ & $(0.0114)$ & $(0.0041)$ \\
\hline Observations & 2,565 & 2,565 & 2,565 & 2,565 & 2,565 & 2,565 \\
\hline Clusters & 47 & 47 & 47 & 47 & 47 & 47 \\
\hline
\end{tabular}

***; ${ }^{* * *}$; and ${ }^{*}=$ statistically different from zero at the $1 \% ; 5 \%$; and $10 \%$ level, respectively.

Notes: All models estimated with OLS and control for potential experience, demographics, school leaving state fixed effects, and school leaving year fixed effects. NLSY79 sample weights applied. Standard errors reported in parentheses and clustered around the school leaving state.

Among women leaving school in an economic downturn appears to shift the sleep distribution to the right: away from the shortest sleeps (less than $5 \mathrm{~h}$ per night) and toward longer sleeps. In particular, the coefficient estimates on the school-leaving state unemployment rate in regressions of all measures of longer sleep carry a positive sign, although the coefficient estimates are not statistically different from zero.

Before preceding to our 2SLS results, we report first stage regressions in the sleep quantity sample and associated $F$ statistics (Table 16). As in the sleep quality sample, the instruments are powerful predictors of the school-leaving state unemployment rate. The $F$ statistic is 34 in the male sample and 32 in the female sample. Moreover, a 1 percentage point increase in the on time state unemployment rate leads to a 0.24 percentage point $(3.4 \%)$ increase in the school-leaving state unemployment rate for both men and women $(p<0.01)$.

Table 16: First stage OLS regressions: NLSY79 50 and Over Health Module sleep quantity sample. 


\begin{tabular}{lll}
\hline Sample & Men & Women \\
\hline Sample mean & 7.1612 & 7.2094 \\
On time state unemployment rate & $0.2444^{* * *}$ & $0.2441^{* * *}$ \\
& $(0.0419)$ & $(0.0430)$ \\
F statistic on the on time school & $34.00(0.0000)$ & $32.26(0.0000)$ \\
leaving state unemployment rate $(p$ & & \\
value) & 2,361 & 2,565 \\
Observations & 49 & 47 \\
Clusters & & \\
\hline
\end{tabular}

***; **; and * statistically different from zero at the $1 \% ; 5 \%$; and $10 \%$ level, respectively.

Notes: The outcome variable in all regressions in the school leaving state unemployment rate. All models estimated with OLS and control for potential experience, demographics, on time school leaving state fixed effects, and on time school leaving year fixed effects. NLSY79 sample weights applied. Standard errors reported in parentheses and clustered around the school leaving state.

The results generated in 2SLS regressions are reported in Table 17. Among men, we find a mixed pattern of results: there is some evidence that leaving school in an economic downturn may shift men away from the shortest sleeps measured here (less than $5 \mathrm{~h}$ per night). Moreover, we find that a 1 percentage point increase in the school-leaving state unemployment rate increases the propensity for sleeps between 5 to less than $6 \mathrm{~h}$ by $2.6 \%$ and between $6 \mathrm{~h}$ to less than $7 \mathrm{~h}$ by $5.7 \%$. On the other hand, the same increase in the school-leaving state unemployment rate decreases the probability of sleep durations of $7 \mathrm{~h}$ to less than $8 \mathrm{~h}$ by $1.6 \%$ and sleep durations of $8 \mathrm{~h}$ to less than $9 \mathrm{~h}$ by $10.0 \%$. Leaving school in an economic downturn increases the probability of the longest sleep duration we examine here: 9 or more hours per night. Overall, the 2SLS estimates suggest that leaving school in an economic downturn shifts men's sleep distribution toward longer sleeps, although the distribution may be dispersed away from middle range sleeps (i. e. 7 to less than $9 \mathrm{~h}$ per night).

Table 17: Effect of leaving school in a recession on sleep quantity: 2SLS model NLSY79 50 and Over Health Module sleep quantity sample.

\begin{tabular}{|c|c|c|c|c|c|c|}
\hline Outcome & Sleep $<5 \mathrm{~h}$ & Sleep $5-<6 h$ & Sleep $6-<7 \mathrm{~h}$ & Sleep $7-<8 \mathrm{~h}$ & Sleep $8-<9 h$ & Sleep 9+h \\
\hline \multicolumn{7}{|l|}{ Men } \\
\hline $\begin{array}{l}\text { Sample } \\
\text { proportion }\end{array}$ & 0.0604 & 0.1039 & 0.2751 & 0.3243 & 0.2056 & 0.0306 \\
\hline School & -0.0007 & 0.0027 & 0.0158 & -0.0052 & -0.0205 & 0.0078 \\
\hline $\begin{array}{l}\text { leaving } \\
\text { state UE rate }\end{array}$ & $(0.0054)$ & $(0.0125)$ & $(0.0167)$ & $(0.0183)$ & $(0.0166)$ & $(0.0055)$ \\
\hline Observations & 2,361 & 2,361 & 2,361 & 2,361 & 2,361 & 2,361 \\
\hline $\begin{array}{l}\text { Clusters } \\
\text { Women }\end{array}$ & 46 & 46 & 46 & 46 & 46 & 46 \\
\hline $\begin{array}{l}\text { Sample } \\
\text { proportion }\end{array}$ & 0.0541 & 0.0964 & 0.2581 & 0.3123 & 0.2352 & 0.0439 \\
\hline School & $-0.0247^{*}$ & 0.0017 & 0.0052 & -0.0043 & 0.0182 & 0.0039 \\
\hline $\begin{array}{l}\text { leaving } \\
\text { state UE rate }\end{array}$ & $(0.0127)$ & $(0.0089)$ & $(0.0138)$ & $(0.0118)$ & (0.0149) & $(0.0100)$ \\
\hline Observations & 2,565 & 2,565 & 2,565 & 2,565 & 2,565 & 2,565 \\
\hline Clusters & 46 & 46 & 46 & 46 & 46 & 46 \\
\hline
\end{tabular}

$* * * * ;$; and $*$ statistically different from zero at the $1 \% ; 5 \%$; and $10 \%$ level, respectively.

Notes: All models estimated with 2SLS and control for potential experience, demographics, on time school leaving state fixed effects, and on time school leaving year fixed effects. NLSY79 sample weights applied. Standard errors reported in parentheses and clustered around the on time school leaving state.

Broadly, leaving school in an economic downturn shifts women's sleep duration distribution to the right: there is a decrease in the probability of reporting the shortest sleep duration (less than $5 \mathrm{~h}$ per night) and toward the probability of reporting longer sleep durations. One exception is the probability of sleeping 7 to less than $8 \mathrm{~h}$ per night: the coefficient estimate in this regression carries a negative sign.

We next examine heterogeneity in sleep quantity effects by skill, ability, race and ethnicity, and educational credentials using the group definitions outlined in Section 4.4 (for brevity, we report 2SLS results only). First stage regression results and associated $F$ statistics for each of these subgroups are reported in Table 18. In general, and comparable to the sleep quality sample results, we find evidence that the IVs are strong predictors of the school-leaving state unemployment rate. The coefficient estimates are all positive, suggesting that increases in the on time state unemployment rate lead to increases in the school-leaving state unemployment rate for all of the groups we examine. We find evidence that our IVs are strong: the $F$ statistics on the IV are generally at 
or above accepted minimum values within the economics literature (Stock and Yogo 2005). However, there are some subgroups for whom the IV may be weak (e.g. high-skill and credentialed women). We note weak IVs for these subgroups as a limitation of the study and encourage readers to interpret findings for these groups with caution.

Table 18: Heterogeneity across sub-groups in first stage OLS regressions: NLSY79 50 and Over Health Module.

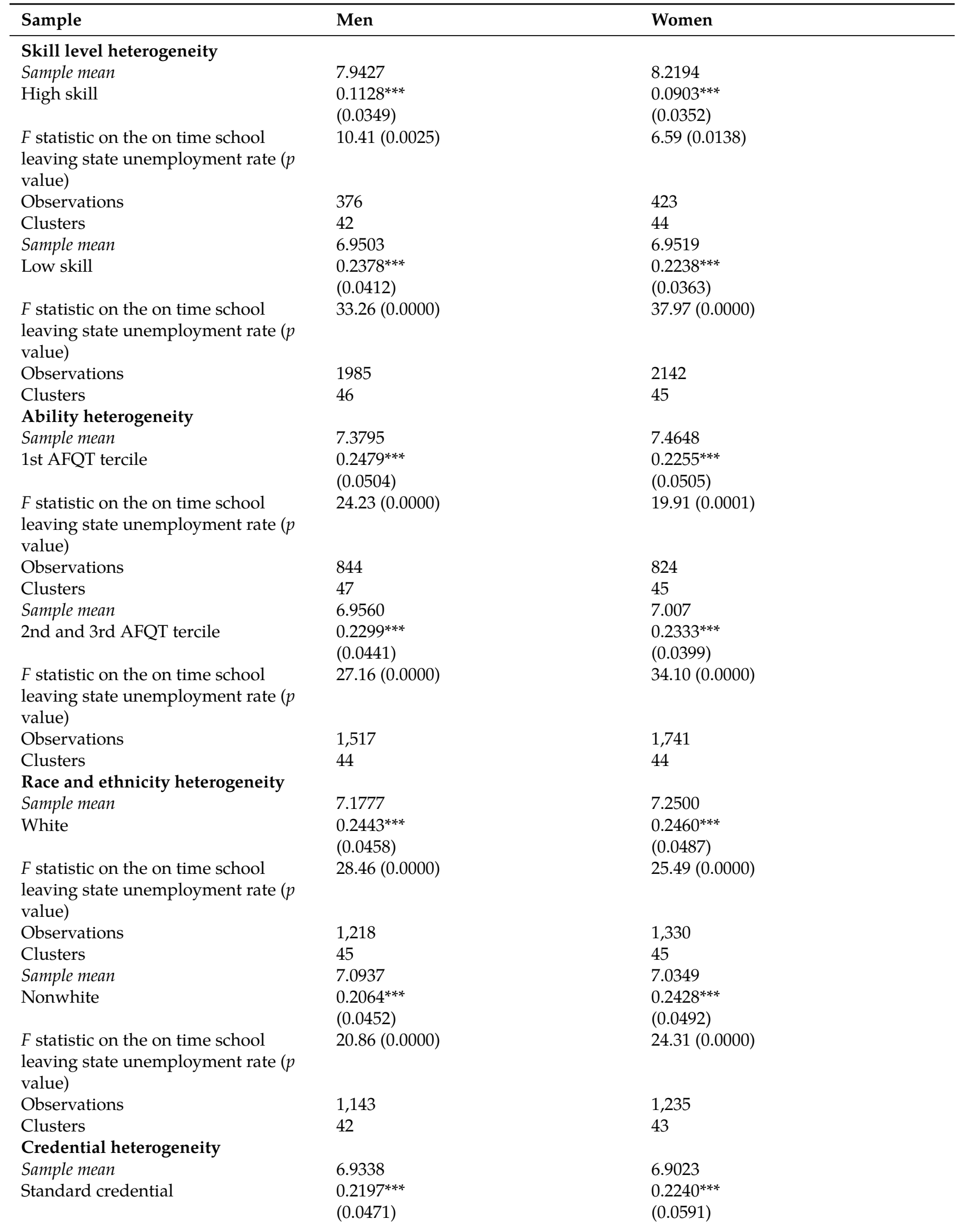




$\begin{array}{lll}\begin{array}{l}\text { F statistic on the on time school } \\ \text { leaving state unemployment rate }(p\end{array} & 21.79(0.0000) & 14.34(0.0005) \\ \text { value) } & & \\ \begin{array}{l}\text { Observations } \\ \text { Clusters }\end{array} & 842 & 918 \\ \begin{array}{l}\text { Sample mean } \\ \text { Nonstandard credential }\end{array} & 7.2995 & 45 \\ & 0.2095^{* * *} & 7.4039 \\ \begin{array}{l}\text { F statistic on the on time school } \\ \text { leaving state unemployment rate }(p\end{array} & (0.0352) & 0.2159^{* * *} \\ \text { value) } & 35.52(0.0000) & (0.0496) \\ \text { Observations } & & 18.98(0.0001) \\ \text { Clusters } & 1,519 & \\ \end{array}$

${ }^{* * * * * * *} ;$ and ${ }^{*}=$ statistically different from zero at the $1 \% ; 5 \%$; and $10 \%$ level, respectively.

Notes: The outcome in all regressions in the school leaving state unemployment rate. All models estimated with OLS and control for potential experience, demographics, on time school leaving state fixed effects, and on time school leaving year fixed effects. NLSY79 sample weights applied. Standard errors reported in parentheses and clustered around the on time school leaving state.

Table 19-Table 22 report heterogeneity in the sleep quantity effects by worker skill, ability, race and ethnicity, and educational credentials. We estimate numerous regressions in our analysis of heterogeneity in sleep quantity effects and most estimates are not statistically different from zero (potentially due to the fact that our sleep quantity samples are small to begin with and stratification worsens our small sample problems). Thus, we chose to discuss the broad patterns we observe for each subgroup rather than specific point estimates. In particular, we focus on whether leaving school in an economic downturn shifts, compresses, or disperses the sleep quantity distribution for the subpopulations we study here.

Table 19: Heterogeneity by skill level in the effect of leaving school in a recession on sleep quantity: 2SLS model NLSY79 50 and Over Health Module sleep quantity sample.

\begin{tabular}{|c|c|c|c|c|c|c|}
\hline Outcome & Sleep $<5 \mathrm{~h}$ & Sleep $5-<6 h$ & Sleep $6-<7 \mathrm{~h}$ & Sleep $7-<8$ h & Sleep $8-<9 h$ & Sleep 9+h \\
\hline \multicolumn{7}{|l|}{ High-skill men } \\
\hline $\begin{array}{l}\text { Sample } \\
\text { proportion }\end{array}$ & 0.0203 & 0.0550 & 0.2714 & 0.4562 & 0.1940 & 0.0031 \\
\hline School & 0.0224 & $0.0594^{*}$ & 0.0607 & -0.0427 & $-0.1004^{*}$ & 0.0006 \\
\hline $\begin{array}{l}\text { leaving } \\
\text { state UE rate }\end{array}$ & $(0.0171)$ & $(0.0337)$ & $(0.0748)$ & $(0.0669)$ & $(0.0518)$ & $(0.0027)$ \\
\hline Observations & 376 & 376 & 376 & 376 & 376 & 376 \\
\hline Clusters & 39 & 39 & 39 & 39 & 39 & 39 \\
\hline Low-skill men & & & & & & \\
\hline $\begin{array}{l}\text { Sample } \\
\text { proportion }\end{array}$ & 0.0713 & 0.1171 & 0.2761 & 0.2887 & 0.2087 & 0.0380 \\
\hline School & -0.0059 & -0.0054 & 0.0198 & 0.0078 & $-0.0283^{*}$ & $0.0120^{*}$ \\
\hline $\begin{array}{l}\text { leaving } \\
\text { state UE rate }\end{array}$ & $(0.0087)$ & $(0.0175)$ & $(0.0167)$ & $(0.0194)$ & $(0.0172)$ & $(0.0072)$ \\
\hline Observations & 1,985 & 1,985 & 1,985 & 1,985 & 1,985 & 1,985 \\
\hline $\begin{array}{l}\text { Clusters } \\
\text { High-skill } \\
\text { women }\end{array}$ & 46 & 46 & 46 & 46 & 46 & 46 \\
\hline $\begin{array}{l}\text { Sample } \\
\text { proportion }\end{array}$ & 0.0604 & 0.1039 & 0.2751 & 0.3243 & 0.2056 & 0.0306 \\
\hline School & -0.0050 & -0.0664 & -0.2123 & 0.2090 & -0.0034 & 0.0780 \\
\hline $\begin{array}{l}\text { leaving } \\
\text { state UE rate }\end{array}$ & $(0.0496)$ & $(0.0748)$ & $(0.3229)$ & $(0.2469)$ & $(0.1055)$ & $(0.1786)$ \\
\hline Observations & 423 & 423 & 423 & 423 & 423 & 423 \\
\hline $\begin{array}{l}\text { Clusters } \\
\text { Low-skill } \\
\text { women }\end{array}$ & 40 & 40 & 40 & 40 & 40 & 40 \\
\hline $\begin{array}{l}\text { Sample } \\
\text { proportion }\end{array}$ & 0.0635 & 0.1019 & 0.2632 & 0.2905 & 0.2357 & 0.0452 \\
\hline School & -0.0183 & 0.0136 & 0.0011 & -0.0046 & 0.0147 & -0.0064 \\
\hline state UE rate & $(0.0121)$ & (0.0110) & $(0.0137)$ & $(0.0156)$ & $(0.0168)$ & $(0.0084)$ \\
\hline Observations & 2,142 & 2,142 & 2,142 & 2,142 & 2,142 & 2,142 \\
\hline Clusters & 45 & 45 & 45 & 45 & 45 & 45 \\
\hline
\end{tabular}


$* * * * *$; and $*$ statistically different from zero at the $1 \% ; 5 \%$; and $10 \%$ level, respectively.

Notes: All models estimated with 2SLS and control for potential experience, demographics, on time school leaving state fixed effects, and on time school leaving year fixed effects. NLSY79 sample weights applied. Standard errors reported in parentheses and clustered around the on time school leaving state.

Among higher skill men (Table 19), we find evidence that leaving school in an economic downturn shifts the sleep distribution to the left, that is those high-skill men who leave school when the state unemployment rate is high are more likely to report both lower sleep quantity and more likely to report higher sleep quantity, but overall it appears that the sleep distribution is shifted to the left which reflects shorter sleeps. We observe a contrasting distributional shift among lower skill men: leaving school in an economic downturn appears to shift the sleep duration distribution to the right, away from short duration sleep and toward long duration sleep. In the female sample(Table 20), the sleep distribution for high-skill women who leave school in an economic downturn is shifted to the right (i. e. sleep duration broadly increases overall for such women). However, among lower skill women, leaving school in an economic downturn appears to compress the sleep quantity distribution. In other words, we see decreases (increases) in the probability of reporting both short and long sleep duration (midrange sleep duration, in particular sleeping 6 to less than $7 \mathrm{~h}$ per night).

Table 20: Heterogeneity by ability level in the effect of leaving school in a recession on sleep quantity: 2SLS model NLSY79 50 and Over Health Module sleep quantity sample.

\begin{tabular}{|c|c|c|c|c|c|c|}
\hline Outcome & Sleep $<5 \mathrm{~h}$ & Sleep 5-<6h & Sleep $6-<7 \mathrm{~h}$ & Sleep $7-<8 \mathrm{~h}$ & Sleep 8-<9h & Sleep $9+\mathrm{h}$ \\
\hline $\begin{array}{l}\text { Men in 1st } \\
\text { AFQT tercile }\end{array}$ & & & & & & \\
\hline $\begin{array}{l}\text { Sample } \\
\text { proportion }\end{array}$ & 0.0397 & 0.0852 & 0.2654 & 0.3967 & 0.1937 & 0.0195 \\
\hline $\begin{array}{l}\text { School } \\
\text { leaving }\end{array}$ & 0.0144 & 0.0104 & -0.0151 & -0.0039 & -0.0164 & 0.0106 \\
\hline state UE rate & $(0.0090)$ & $(0.0135)$ & $(0.0279)$ & $(0.0265)$ & $(0.0185)$ & $(0.0091)$ \\
\hline Observations & 844 & 844 & 844 & 844 & 844 & 844 \\
\hline $\begin{array}{l}\text { Clusters } \\
\text { Men in 2nd } \\
\text { and } 3 r d \text { AFQT } \\
\text { tercile }\end{array}$ & 44 & 44 & 44 & 44 & 44 & 44 \\
\hline $\begin{array}{l}\text { Sample } \\
\text { proportion }\end{array}$ & 0.0799 & 0.1216 & 0.2841 & 0.2564 & 0.2170 & 0.0410 \\
\hline $\begin{array}{l}\text { School } \\
\text { leaving }\end{array}$ & -0.0097 & -0.0076 & $0.0502^{* *}$ & -0.0240 & -0.0204 & 0.0115 \\
\hline state UE rate & $(0.0101)$ & $(0.0176)$ & $(0.0244)$ & $(0.0179)$ & $(0.0237)$ & $(0.0100)$ \\
\hline Observations & 1,517 & 1,517 & 1,517 & 1,517 & 1,517 & 1,517 \\
\hline $\begin{array}{l}\text { Clusters } \\
\text { Women in 1st } \\
\text { AFQT tercile }\end{array}$ & 45 & 45 & 45 & 45 & 45 & 45 \\
\hline $\begin{array}{l}\text { Sample } \\
\text { proportion }\end{array}$ & 0.0266 & 0.0837 & 0.2349 & 0.3774 & 0.2328 & 0.0446 \\
\hline $\begin{array}{l}\text { School } \\
\text { leaving }\end{array}$ & $-0.0313^{* * *}$ & 0.0003 & -0.0067 & -0.0120 & 0.0128 & $0.0369^{* *}$ \\
\hline state UE rate & $(0.0117)$ & $(0.0193)$ & $(0.0222)$ & $(0.0249)$ & $(0.0185)$ & $(0.0175)$ \\
\hline Observations & 824 & 824 & 824 & 824 & 824 & 824 \\
\hline $\begin{array}{l}\text { Clusters } \\
\text { Women in 2nd } \\
\text { and 3rd AFQT } \\
\text { tercile }\end{array}$ & 42 & 42 & 42 & 42 & 42 & 42 \\
\hline $\begin{array}{l}\text { Sample } \\
\text { proportion }\end{array}$ & 0.0758 & 0.1065 & 0.2765 & 0.2609 & 0.2371 & 0.0434 \\
\hline $\begin{array}{l}\text { School } \\
\text { leaving }\end{array}$ & -0.0153 & -0.0010 & 0.0072 & 0.0039 & 0.0195 & $-0.0143^{*}$ \\
\hline state UE rate & $(0.0128)$ & $(0.0125)$ & $(0.0208)$ & $(0.0152)$ & $(0.0222)$ & $(0.0085)$ \\
\hline Observations & 1,741 & 1,741 & 1,741 & 1,741 & 1,741 & 1,741 \\
\hline Clusters & 44 & 44 & 44 & 44 & 44 & 44 \\
\hline
\end{tabular}

***; ${ }^{* * *}$; and $*$ = statistically different from zero at the $1 \% ; 5 \%$; and $10 \%$ level, respectively.

Notes: All models estimated with 2SLS and control for potential experience, demographics, on time school leaving state fixed effects, and on time school leaving year fixed effects. NLSY79 sample weights applied. Standard errors reported in parentheses and clustered around the on time school leaving state. 
Table 20 reports regression results from our analysis of heterogeneity by worker ability. The sleep quantity of high and low ability men is differentially impacted by leaving school in an economic downturn. On the one hand, the sleep quantity distribution of high-ability men is dispersed (i. e. those men who leave school in an economic downturn are more likely to report both short and long sleeps, and less likely to report midrange sleeps). Alternatively, overall we find that leaving school in an economic downturn compresses the sleep quantity distribution of lower ability men toward midrange sleeps. Higher ability women who leave school in an economic downturn appear to increase sleep duration (i. e. overall the sleep distribution for such women shifts to the right) while lower ability women who leave school in an economic downturn experience reduction in very short and long sleeps and increases in midrange sleeps (i. e. the sleep distribution is compressed).

Both white men and women who leave school in an economic downturn sleep more than otherwise similar white men and women (Table 21). That is, the overall sleep distribution shifts to the right for such individuals. Nonwhite men leave school in an economic downturn sleep less than comparable individuals. The coefficient estimates in the nonwhite female sample suggest that nonwhite women who leave school in an economic downturn are more likely to report midrange sleeps than long or short sleeps (i. e. the sleep distribution is compressed).

Table 21: Heterogeneity by race and ethnicity in the effect of leaving school in a recession on sleep quantity: 2SLS model NLSY79 50 and Over Health Module sleep quantity sample.

\begin{tabular}{|c|c|c|c|c|c|c|}
\hline Outcome & Sleep $<5 \mathrm{~h}$ & Sleep 5-<6h & Sleep $6-<7 \mathrm{~h}$ & Sleep $7-<8$ h & Sleep $8-<9 h$ & Sleep 9+h \\
\hline White men & & & & & & \\
\hline $\begin{array}{l}\text { Sample } \\
\text { proportion }\end{array}$ & 0.0517 & 0.0949 & 0.2690 & 0.3576 & 0.1997 & 0.0271 \\
\hline School & -0.0066 & -0.0041 & 0.0190 & 0.0078 & -0.0275 & 0.0115 \\
\hline $\begin{array}{l}\text { leaving } \\
\text { state UE rate }\end{array}$ & $(0.0051)$ & $(0.0141)$ & $(0.0184)$ & $(0.0212)$ & $(0.0212)$ & $(0.0075)$ \\
\hline Observations & 1,218 & 1,218 & 1,218 & 1,218 & 1,218 & 1,218 \\
\hline $\begin{array}{l}\text { Clusters } \\
\text { Nonwhite men }\end{array}$ & 44 & 44 & 44 & 44 & 44 & 44 \\
\hline $\begin{array}{l}\text { Sample } \\
\text { proportion }\end{array}$ & 0.0963 & 0.1408 & 0.3000 & 0.1880 & 0.2300 & 0.0450 \\
\hline $\begin{array}{l}\text { School } \\
\text { leaving }\end{array}$ & 0.0172 & 0.0314 & 0.0231 & $-0.0541^{* *}$ & -0.0078 & -0.0099 \\
\hline state UE rate & $(0.0195)$ & $(0.0220)$ & $(0.0259)$ & $(0.0211)$ & $(0.0341)$ & $(0.0184)$ \\
\hline Observations & 1,143 & 1,143 & 1,143 & 1,143 & 1,143 & 1,143 \\
\hline $\begin{array}{l}\text { Clusters } \\
\text { White women }\end{array}$ & 43 & 43 & 43 & 43 & 43 & 43 \\
\hline $\begin{array}{l}\text { Sample } \\
\text { proportion }\end{array}$ & 0.0453 & 0.0894 & 0.2515 & 0.3305 & 0.2389 & 0.0444 \\
\hline $\begin{array}{l}\text { School } \\
\text { leaving }\end{array}$ & $-0.0309^{* *}$ & -0.0020 & 0.0085 & -0.0034 & 0.0230 & 0.0047 \\
\hline state UE rate & $(0.0150)$ & $(0.0087)$ & $(0.0164)$ & $(0.0146)$ & $(0.0158)$ & $(0.0122)$ \\
\hline Observations & 1,330 & 1,330 & 1,330 & 1,330 & 1,330 & 1,330 \\
\hline $\begin{array}{l}\text { Clusters } \\
\text { Nonwhite } \\
\text { women }\end{array}$ & 43 & 43 & 43 & 43 & 43 & 43 \\
\hline $\begin{array}{l}\text { Sample } \\
\text { proportion }\end{array}$ & 0.0916 & 0.1266 & 0.2865 & 0.2343 & 0.2190 & 0.0420 \\
\hline $\begin{array}{l}\text { School } \\
\text { leaving }\end{array}$ & -0.0073 & $0.0265^{* *}$ & 0.0087 & 0.0075 & -0.0251 & -0.0103 \\
\hline state UE rate & $(0.0170)$ & $(0.0125)$ & $(0.0251)$ & $(0.0237)$ & $(0.0291)$ & $(0.0091)$ \\
\hline Observations & 1,235 & 1,235 & 1,235 & 1,235 & 1,235 & 1,235 \\
\hline Clusters & 42 & 42 & 42 & 42 & 42 & 42 \\
\hline
\end{tabular}

${ }_{* * * * * *}^{* *}$; and ${ }^{*}=$ statistically different from zero at the $1 \% ; 5 \%$; and $10 \%$ level, respectively.

Notes: All models estimated with 2SLS and control for potential experience, demographics, on time school leaving state fixed effects, and on time school leaving year fixed effects. NLSY79 sample weights applied. Standard errors reported in parentheses and clustered around the on time school leaving state.

Finally, we explore heterogeneity across educational credentials at school leaving. Recall that the purpose of our exploration into this margin of worker heterogeneity is to examine the hypothesis that our instruments may be more accurately defined for those individuals who leave school with a standard credential and/or that there are differences in the risk of violating the exclusion restriction across standard and nonstandard credentialed individuals. Results from this analysis are reported in Table 22. Men who leave school with a standard credential 
are less likely to report midrange sleeps and more likely to report either short or long sleep if they leave school in an economic downturn (thus, their sleep duration distribution is dispersed). On the other hand, nonstandard credentialed men who leave school in an economic downturn are more likely to report midrange sleep duration (i. e. their sleep duration distribution is compressed). Standard credentialed women who leave school in an economic downturn are more (less) likely to experience midrange (i. e. both short and long sleeps) sleeps while nonstandard credentialed women sleep more (i. e. the sleep distribution for such women shifts to the right).

Table 22: Heterogeneity by educational credential in the effect of leaving school in a recession on sleep quantity: 2SLS model NLSY79 50 and Over Health Module sleep quantity sample.

\begin{tabular}{|c|c|c|c|c|c|c|}
\hline Outcome & Sleep $<5 \mathrm{~h}$ & Sleep 5-<6h & Sleep $6-<7 \mathrm{~h}$ & Sleep $7-<8$ h & Sleep $8-<9 h$ & Sleep $9+\mathrm{h}$ \\
\hline \multicolumn{7}{|l|}{$\begin{array}{l}\text { Standard } \\
\text { credential men }\end{array}$} \\
\hline $\begin{array}{l}\text { Sample } \\
\text { proportion }\end{array}$ & 0.0568 & 0.1010 & 0.2947 & 0.3020 & 0.2129 & 0.0326 \\
\hline School & $0.0266^{*}$ & $-0.0334^{*}$ & -0.0184 & -0.0118 & 0.0064 & $0.0307^{*}$ \\
\hline $\begin{array}{l}\text { leaving } \\
\text { state UE rate }\end{array}$ & $(00139)$ & (0 0175) & $(\cap \Omega 401)$ & $(0,0505)$ & $(00279)$ & $(00145)$ \\
\hline Observations & 842 & $\begin{array}{l}(0.01 / 5) \\
842\end{array}$ & $\begin{array}{l}(0.0401) \\
842\end{array}$ & $\begin{array}{l}(0.0505) \\
842\end{array}$ & $\begin{array}{l}(0.03 / 9) \\
842\end{array}$ & $\begin{array}{l}(0.0145) \\
842\end{array}$ \\
\hline Clusters & 45 & 45 & 45 & 45 & 45 & 45 \\
\hline \multicolumn{7}{|l|}{$\begin{array}{l}\text { Nonstandard } \\
\text { credential men }\end{array}$} \\
\hline $\begin{array}{l}\text { Sample } \\
\text { proportion }\end{array}$ & 0.0626 & 0.1057 & 0.2632 & 0.3379 & 0.2012 & 0.0294 \\
\hline School & $-0.0145^{*}$ & 0.0173 & 0.0287 & 0.0005 & $-0.0311^{*}$ & -0.0007 \\
\hline leaving & & & & & & \\
\hline state UE rate & $(0.0087)$ & $(0.0169)$ & $(0.0265)$ & $(0.0244)$ & $(0.0162)$ & $(0.0069)$ \\
\hline Observations & 1,519 & 1,519 & 1,519 & 1,519 & 1,519 & 1,519 \\
\hline Clusters & 44 & 44 & 44 & 44 & 44 & 44 \\
\hline \multicolumn{7}{|l|}{$\begin{array}{l}\text { Standard } \\
\text { credential } \\
\text { women }\end{array}$} \\
\hline $\begin{array}{l}\text { Sample } \\
\text { proportion }\end{array}$ & 0.0419 & 0.1143 & 0.2687 & 0.2902 & 0.2376 & 0.0472 \\
\hline School & -0.0322 & 0.0033 & 0.0092 & -0.0269 & 0.0544 & -0.0079 \\
\hline leaving & & & & & & \\
\hline state UE rate & $(0.0225)$ & $(0.0228)$ & $(0.0239)$ & $(0.0341)$ & $(0.0442)$ & $(0.0277)$ \\
\hline Observations & 918 & 918 & 918 & 918 & 918 & 918 \\
\hline Clusters & 42 & 42 & 42 & 42 & 42 & 42 \\
\hline \multicolumn{7}{|l|}{$\begin{array}{l}\text { Nonstandard } \\
\text { credential } \\
\text { women }\end{array}$} \\
\hline $\begin{array}{l}\text { Sample } \\
\text { proportion }\end{array}$ & 0.0618 & 0.0851 & 0.2513 & 0.3263 & 0.2336 & 0.0418 \\
\hline School & $-0.0272^{* *}$ & 0.0125 & -0.0011 & 0.0051 & 0.0062 & 0.0045 \\
\hline leaving & & & & & & \\
\hline state UE rate & $(0.0123)$ & $(0.0126)$ & $(0.0180)$ & $(0.0170)$ & $(0.0117)$ & $(0.0105)$ \\
\hline Observations & 1,647 & 1,647 & 1,647 & 1,647 & 1,647 & 1,647 \\
\hline Clusters & 45 & 45 & 45 & 45 & 45 & 45 \\
\hline
\end{tabular}

$* * * * * ;$ and $*$ statistically different from zero at the $1 \% ; 5 \%$; and $10 \%$ level, respectively.

Notes: All models estimated with 2 SLS and control for potential experience, demographics, on time school leaving state fixed effects, and on time school leaving year fixed effects. NLSY79 sample weights applied. Standard errors reported in parentheses and clustered around the on time school leaving state.

\subsection{Pathways through which Leaving School in an Economic Downturn may Impact Sleep}

We next explore several possible labor and marriage market pathways through which leaving school in an economic downturn may impact sleep outcomes. We focus on the sleep quantity sample. Table 23 (labor market) and 24 (marriage market) report results from this analysis. These potential mechanisms are measured cumulatively from the period of school leaving through the time at which a sleep variable is measured. ${ }^{29}$ In terms of labor market earnings (i. e. earnings from salary and wages), we find that men (but not women) who leave 
school in an economic downturn have lower labor market earnings, and this penalty is statistically distinguishable from zero 15 years after school leaving. More specifically, a 1 percentage point increase in the school-leaving state unemployment rate leads to a $9.7 \%$ and $6.8 \%$ reduction in cumulative earnings at $6-10$ and $11-15$ years after school leaving. Coefficient estimates on indicators from more distal time periods carry a negative sign but are smaller in magnitude and imprecise. The duration and the magnitude of this effect is broadly comparable to labor studies of the wage and earnings effects of leaving school in an economic downturn (Kahn 2010; Altonji, Kahn, and Speer 2014).

Table 23: Effect of economic conditions faced at school leaving on cumulative labor market outcomes: NLSY79 2SLS model.

\begin{tabular}{|c|c|c|c|}
\hline Outcome & Log(earnings) & Number of jobs & Weeks worked \\
\hline \multicolumn{4}{|l|}{ Men } \\
\hline Sample mean & $523,819.7$ & 10.27 & 833.08 \\
\hline $6-10$ years potential & $-0.0966^{* * *}$ & -0.1574 & -6.6161 \\
\hline experience & $(0.0331)$ & $(0.1722)$ & $(4.0937)$ \\
\hline 11-15 years potential & $-0.0675^{*}$ & -0.1127 & -3.0843 \\
\hline experience & $(0.0346)$ & $(0.1786)$ & $(4.2830)$ \\
\hline $16-20$ years potential & -0.0288 & -0.1119 & 3.5683 \\
\hline experience & $(0.0324)$ & $(0.1781)$ & $(3.5046)$ \\
\hline 21-25 years potential & -0.0412 & -0.0376 & 3.5382 \\
\hline experience & $(0.0308)$ & $(0.1871)$ & $(3.8956)$ \\
\hline 26-37 years potential & -0.0427 & -0.0892 & 8.1579 \\
\hline experience & $(0.0317)$ & $(0.2023)$ & $(5.2991)$ \\
\hline Observations & 13,479 & 13,479 & 13,479 \\
\hline Clusters & 48 & 48 & 48 \\
\hline \multicolumn{4}{|l|}{ Women } \\
\hline Sample mean & $309,566.9$ & 9.59 & 695.56 \\
\hline $6-10$ years potential & -0.0042 & -0.1036 & 0.4452 \\
\hline experience & $(0.0375)$ & $(0.1273)$ & $(6.6814)$ \\
\hline $11-15$ years potential & -0.0195 & -0.0563 & -5.0504 \\
\hline experience & $(0.0314)$ & $(0.1353)$ & $(6.1777)$ \\
\hline 16-20 years potential & 0.0002 & -0.1199 & 1.7067 \\
\hline experience & $(0.0333)$ & $(0.1334)$ & $(6.0511)$ \\
\hline 21-25 years potential & -0.0028 & -0.0579 & -1.6191 \\
\hline experience & $(0.0319)$ & $(0.1513)$ & $(5.9736)$ \\
\hline 26-37 years potential & -0.0119 & -0.2053 & 1.1362 \\
\hline experience & $(0.0364)$ & $(0.1721)$ & $(6.6918)$ \\
\hline Observations & 14,124 & 14,124 & 14,124 \\
\hline Clusters & 48 & 48 & 48 \\
\hline
\end{tabular}

***; **; and ${ }^{*}=$ statistically different from zero at the $1 \% ; 5 \%$; and $10 \%$ level, respectively.

Notes: All models estimated with $2 \mathrm{SLS}$ and control for potential experience, demographics, on time school leaving state fixed effects, and on time school leaving year fixed effects. NLSY79 sample weights applied. Standard errors reported in parentheses and clustered around the on time school leaving state.

Table 24: Effect of economic conditions faced at school leaving on cumulative marriage market outcomes: NLSY79 2SLS model.

\begin{tabular}{lll}
\hline Outcome & Number of partners & Number of children \\
\hline Men & & \\
Sample mean & 1.1732 & 1.4026 \\
6-10years potential experience & 0.0201 & $-0.0934^{* * *}$ \\
& $(0.0269)$ & $(0.0238)$ \\
11-15 years potential experience & 0.0274 & $-0.0439^{*}$ \\
& $(0.0264)$ & $(0.0208)$ \\
16-20 years potential experience & 0.0138 & -0.0224 \\
& $(0.0273)$ & $(0.0218)$ \\
21-25 years potential experience & 0.0259 & -0.0340 \\
& $(0.0276)$ & $(0.0212)$ \\
26-37 years potential experience & -0.0011 & $-0.0699^{* * *}$ \\
& $(0.0305)$ & $(0.0266)$ \\
Observations & 13,479 & 13,479
\end{tabular}


Clusters

Women

Sample mean

6-10 years potential experience

11-15 years potential experience

16-20 years potential experience

21-25 years potential experience

26-37 years potential experience

Observations

Clusters
48

$\begin{array}{ll}1.2821 & 1.6789 \\ -0.0276 & -0.0401^{*} \\ (0.0188) & (0.0224) \\ -0.0354^{*} & 0.0338 \\ (0.0189) & (0.0310) \\ -0.0504^{* * *} & 0.0407 \\ (0.0171) & (0.0298) \\ -0.0399^{* *} & 0.0353 \\ (0.0181) & (0.0349) \\ -0.0699^{* * *} & -0.0076 \\ (0.0231) & (0.0394) \\ 14,124 & 14,124 \\ 48 & 48\end{array}$

${ }^{*} * * *{ }^{* * *}$; and ${ }^{*}=$ statistically different from zero at the $1 \% ; 5 \%$; and $10 \%$ level, respectively.

Notes: All models estimated with 2SLS and control for potential experience, demographics, on time school leaving state fixed effects, and on time school leaving year fixed effects. NLSY79 sample weights applied. Standard errors reported in parentheses and clustered around the on time school leaving state.

In regressions for measures of cumulative number of jobs, we find evidence that men who leave school in an economic downturn hold fewer jobs but the point estimates are not statistically different from zero. Further, our estimates of the effect of leaving school in an economic downturn on cumulative labor supply, although imprecise, suggest that initially (up to 15 years after school leaving), men who leave school in an economic downturn work fewer weeks per year, but, as time passes, such men work more (i. e. 16 years through 37 years after school leaving). Turning to women, we see similar patterns in terms of the sign on the effect of leaving school in an economic downturn, but coefficient estimates are much smaller in magnitude and never statistically different from zero. The effect of leaving school in an economic downturn on cumulative numbers of jobs and weeks worked mirror those for men but as in the male sample the estimates are imprecise.

In terms of marriage market experiences, we find evidence that men who leave school in economic downturn have fewer children and this finding is observable throughout the period over which we are able to track NLSY79 members (thus, these results suggest that we observe quantum effects, not tempo effects). While the coefficient estimates are generally small in magnitude and are never statistically different from zero, we do find evidence that men who left school in an economic downturn have more partners across the life course. We observe statistically significant evidence that women who leave school in an economic downturn have fewer partners and this effects is observable throughout our study period (i. e. up to 37 years after school leaving). We find no precise evidence that women's fertility as measured by the number of children is impacted by economic conditions at school leaving. ${ }^{30}$

To dig deeper into the potential mechanisms through which leaving school in an economic downturn may impact sleep, we conduct a decomposition analysis (Blinder 1973; Oaxaca 1973). Results are reported in Table 26. Among men, we find that the difference in the mean sleep score (share reporting frequent sleep problems) between those who left school when the state unemployment rate was low and those who left school when the state unemployment rate is 0.021 units ( 0.5 percentage points). Based only on differences in endowments between the two groups (the explained portion of the difference in sleep outcomes), we would expect the gaps in the sleep score and the share reporting frequent sleep problems to be 0.036 units and 1.5 percentage points, thus larger than the differences that we observe in the data. The unexplained portion of the difference offsets these differences attributable to endowments: the portion of the differences due to differences in returns and unmeasured factors is negative. In terms of the explained differences across those men who left school when the state unemployment rate was low and high, differences in cumulative labor market experience suggest a difference in the sleep score and the probability of reporting frequent sleep problems of -0.02 units and -0.8 percentage points. Cumulative marriage market experiences offset these differences: the explained differences between the two groups of men based on our marriage market variables suggest differences in the sleep score and the probability of reporting frequent sleep problems of 0.01 units and 0.2 percentage points.

Table 25: Oaxaca Blinder decomposition analysis: NLSY79.

\begin{tabular}{|c|c|c|}
\hline Outcome & Restless sleep (0-3) & Frequent restless sleep \\
\hline Men & & \\
\hline $\begin{array}{l}\text { Sample mean/proportion } \\
\text { Overall differences }\end{array}$ & 1.1732 & 1.4026 \\
\hline $\begin{array}{l}\text { Mean/proportion in low school } \\
\text { leaving state UE rate group }(N=6,488)\end{array}$ & 0.6906 & 0.1838 \\
\hline
\end{tabular}


Mean proportion in high school leaving state UE rate group $(N=6,991)$ Difference

Explained

Unexplained

Explained differences

Labor market mechanisms

Marriage market mechanisms

Observations

Clusters

Women

Sample mean/proportion

Overall differences

Mean/proportion in low school

leaving state UE rate group $(N=6,753)$

Mean proportion in high school

leaving state UE rate group $(N=7,371)$

Difference

Explained

Unexplained

Explained differences

Labor market mechanisms

Marriage market mechanisms

Observations

Clusters
0.6689

0.1792

$0.0217(0.0215)$

$0.0358(0.0218)$

$-0.0141(0.0227)$

$-0.0238^{* *}(0.0121)$

$0.0069^{* *}(0.0027)$

13,479

48

1.2821

0.8902

0.835

$0.0548^{* *}(0.0266)$

$-0.0112(0.0227)$

$0.0660^{* *}(0.0287)$

$-0.0149 *(0.0083)$

$0.0028(0.0022)$

14,124

48
$0.0046(0.0093)$

$0.0151 *(0.0085)$

$-0.0104(0.0084)$

$-0.0082^{*}(0.0044)$

$0.0024^{* *}(0.0010)$

13,479

48

1.6789

0.2508

0.2265

$0.0243^{* *}(0.0104)$

$-0.0060(0.0089)$

$0.03031^{* * *}(0.0109)$

$-0.0062^{*}(0.0034)$

$0.0010(0.0008)$

14,124

48

${ }^{* * * * * * *}$; and ${ }^{*}=$ statistically different from zero at the $1 \% ; 5 \%$; and $10 \%$ level, respectively.

Notes: All models estimated with OLS and control for potential experience, demographics, on time school leaving state fixed effects, and on time school leaving year fixed effects. NLSY79 sample weights applied. Standard errors reported in parentheses and clustered around the on time school leaving state.

Among women, the differences between the two groups are 0.05 units in the sleep score and 2.4 percentage points. Overall, differences in endowments cannot explain these differences (i. e. the explained portions of the differences are not statistically different from zero) and the differences are attributable to differences in returns to endowments and unmeasured factors. However, when examining the portion of the difference explained by difference in endowments, it appears that experiences in the labor market, but not the marriage market, are important for the observed differences in sleep outcomes. Indeed, the labor market endowment differences suggest that differences between the two groups of women would be smaller than the differences we actually observe in the data. Collectively, the findings from our analysis of mechanisms suggests that both labor market and marriage market experiences are important for understanding the sleep effects we observe in the data.

\section{Discussion}

In this study, we provide new evidence on the effects of leaving school in an economic downturn on sleep, as measured by both quality and quantity, using a long panel of individuals drawn from the NLSY79 Cohort. Our findings add to the growing literature that examines the life course effects of leaving school in an economic downturn and the social science literature on factors that determine sleep outcomes.

We find that men who leave school in an economic downturn initially experience lower quality sleep, but these men are able to experience improved sleep quality over time. Women who leave school in an economic downturn experience better sleep quality. In terms of sleep quantity, we find that leaving school in an economic downturn shifts the sleep quantity distribution toward more sleep among men and women. Cumulative labor and marriage market experiences appear to be important mechanisms for the observed sleep effects. We observe heterogeneity in effects across subgroups of the population.

It is reasonable to ask why we observe the nuanced patterns between leaving school in an economic downturn and sleep quality outcomes. In particular, our predictions from economic theory and empirical evidence were not entirely clear and lead to various, often offsetting, pathways through which leaving school in an economic downturn could impact sleep. Among men who leave school in an economic downturn, we observe an inverted U relationship: an initial (6-10 years after school leaving) increase in poor sleep quality followed by a decrease in this probability. Comparing this pattern with labor literature that examines the career effects of leaving school in an economic downturn, we observe that the effects of wages, earnings, and labor supply dissipate between 10 and 15 years in the labor market, which is broadly comparable to the timing of our negative sleep quality effects. Thus, it is plausible that men who leave school in an economic downturn experience depressed 
labor market outcomes early in their career, and these experiences impede their ability to achieve high-quality sleep. The ability of these men to "catch up" in terms of their labor market experiences (i. e. we observe that the estimated earnings penalty becomes statistically indistinguishable from 0 after 10 years) to their peers who left school during stronger economic conditions allows such men to achieve higher quality sleep. One may question why simply "catching up" in terms of labor market outcomes leads to improvements in men's sleep quality. We note that men who leave school in an economic downturn have fewer children, and this finding is persistent throughout the period we are able to track men. Other studies have documented similar fertility effects among American men (Maclean, Covington, and Sikora Kessler 2015). Given that children are linked with worse sleep quality, having fewer children may allow these men to have better quality sleep after their initial labor obstacles have dissipated. Indeed, our decomposition analysis suggests that both labor and marriage market experiences (which includes fertility) are important mechanisms.

Among women, we find that those who leave school in an economic downturn experience declines in the probability of poor quality sleep, although these effects are not immediately statistically different from zero. We do not observe any labor market effects for women, but we do find that women who leave school in an economic downturn have fewer partners. This finding is in line with the hypothesis that these women have fewer marriages and potentially more stable marriages, which favors higher sleep quality. Moreover, it may be that the types of jobs that men and women are able to obtain when they leave school in an economic downturn allow for higher quality sleep, perhaps due to a less stressful work environment in some way that it is not directly reflected in our measures.

We find that, in the full sample, men and women who leave school in an economic downturn sleep more. While economic theory and empirical evidence suggested several, offsetting pathways from leaving school in an economic downturn, overall it appears that the reduced time costs of sleep early in the career combined with reduced childrearing responsibilities (for men) and stabile marriages (for women) permit more sleep. These hypotheses are of course speculative and are not fully satisfactory. A future study with access to richer data on relationships and job characteristics could further explore these possibilities.

Comparing our findings with the economic literature that explores the effect of contemporaneous economic downturns is important for understanding how our findings fit into the broader literature. Overall, the literature suggests that most groups of individuals sleep more during economic downturns. Our results for quantity are broadly in line with these previous findings. In terms of sleep quality, our findings suggest that men who leave school in an economic downturn experience initial increases in poor sleep quality, but this trend is reversed over time. On the other hand, we observe that women experience higher quality sleep. ${ }^{31}$

The literature on contemporaneous economic conditions suggests that sleep quality improves within the working age adult population during downturns. Our findings for men depart from this tendency. One possible reason for the different findings across studies is that different studies focus on different populations of workers. We focus on new labor market entrants who differ from the general working age population in several ways. The former group of workers may (1) be more vulnerable to economic conditions, (2) have accumulated limited financial resources as they are new workers, (3) have limited job search skills to help weather job loss due to reductions in labor demand that occur during downturns, and/or (4) have accumulated college related debt.

Another reason is that we examine the persistent effects of leaving school in an economic downturn, which we argue leads to persistent (although potentially provisional) changes in time costs, income, marriage and fertility propensities, mental health, and drinking practices. We note that previous economic studies focus more on transitory changes. It is plausible that transitory and persistent changes in these factors may have different impacts on sleep outcomes. Finally, we find somewhat stronger effects for white and higher skill/ability males than other workers. The former group of workers, while generally not considered a vulnerable group, may be the most affected by leaving school in an economic downturn in terms of their careers and relative socioeconomic standing. That is, relative income hypotheses and peer effects may be particularly strong for these groups of workers. The relative labor market disadvantage in early career may impede high-quality sleep by creating stress for advantaged men who left school in an economic downturn. Over time, such men are able to obtain higher quality sleep as they recover from their initial hardship in the labor market, and reduced childrearing responsibilities may promote higher sleep quality later in life.

The most comparable study to our research is Guo and Hai (2015). The authors consider the effects of leaving school in an economic downturn on sleep quantity (and other health outcomes) using the National Longitudinal Survey of Youth 1997, thus following respondents through their late 20s and early 30s. We cannot compare our measures of sleep quality with the findings of Guo and Hai because the authors do not consider this outcome; however, we can compare our findings for sleep quantity. Guo and Hai (2015) find that leaving school when the state unemployment rate is high leads to longer sleep duration among high-skilled men (those with a college degree at school leaving) and shorter sleep duration among high-skilled women, with no statistically significant estimates for lower skill (those with a high school diploma at school leaving) men and women. In our analysis, we observe the reverse pattern among higher skill groups: higher skill men tend to sleep less if they leave school 
in an economic downturn and higher skill women tend to sleep more. We find that lower skill men (women) who leave school in an economic downturn sleep less (experience a compressed sleep quantity distribution and a lower propensity for both short and long sleeps).

There are several possible ways to reconcile the findings across the two studies. First, we examine sleep quantity outcomes among workers at a much later stage in their careers than Guo and Hai. We examine workers at roughly age 50 (30 years after school leaving) while Guo and Hai examine workers in their late 20s to early 30s. It is conceivable that the relationship between leaving school in an economic downturn and sleep quantity is nonlinear. Indeed, our findings for sleep quality and previous analyses of the career and human consequences of leaving school in an economic downturn open the door for the possibility of such nonlinearities (Kondo 2015; Maclean and Hill 2015). Second, the two studies exploit variation in economic activity that was generated from two very different recessions. We use variation generated by the recessions of the early 1980s, in particular the recession of 1981-1982. This recession was the largest recession in the post-World War II era prior to the recession of 2008-2010 (National Bureau of Economic Research 2010). One the other hand, the early 2000s recession, which offers variation in the Guo and Hai study, was a relatively mild recession. For example, the recession of 1981-1982 lasted 16 months while the early 2000s recession lasted just 8 months. Moreover, the 1981-1982 recession is referred to as a "double dip" recession as it was preceded by a smaller recession in 1980. While recessions generally negatively impact workers nationwide, recessions are often concentrated in different sectors of the economy, which may lead to different types of workers experiencing different degrees of labor market hardship across recessions. Relatedly, the reduced form effects estimated by both studies reflect the net effect of a complex and offsetting set of income, substitution, work time, and noneconomic effects. The relative importance of these effects also plausibly differ across recessions. While Guo and Hai (2015) employ a continuous specification of sleep quantity, we employ a finer categorization of sleep quantity which potentially allows us to explore the distribution of sleep quantity effects more flexibly. Finally, due to our relatively small sample size, many of our coefficient estimates are imprecise; thus, it is hard to draw strong conclusions regarding the differences in findings between our study and the work of Guo and Hai. Ultimately, we view our study and the study by Guo and Hai as compliments, not substitutes, as together these two studies shed new light on the lifetime consequences for an important economic resource (sleep) attributable to leaving school in an economic downturn.

Our analyses confirm previous research showing that individuals who leave school have persistent differences in their health (Maclean 2013). However, collectively, the emerging body of work on the life course health effects of leaving school in an economic downturn appears to be outcome and population specific. Put differently, Maclean (2013) shows that men who leave school in an economic downturn have worse health at age 40 than comparable men who leave school in more prosperous economic conditions while women may experience some mental health gains from leaving school in an economic downturn. Interpreting our findings in the context of Maclean's work, it is conceivable that the physical health declines experienced by men are offset by their improved sleep outcomes later in life. While some of the mental health gains experienced by women may be attributable to sleep, the health impacts of leaving school in an economic downturn are not straightforward. For example, in a related study, Maclean (2016) shows that men who leave school in an economic downturn have lower body weight than men who do not leave school in an economic downturn while women's body weight is not appreciably impacted by economic conditions at school leaving. One interpretation of these studies is that reliance on a particular measure of health or health behavior is unlikely to provide complete information on the human consequences of leaving school in an economic downturn. This finding is comparable to the labor literature which has explored the effects of leaving school in an economic downturn on a wide range of employment outcomes, and the effects are not entirely homogenous across the considered outcomes.

Our study has several limitations. First, we rely on one cohort of school leavers. This cohort left school before, during, and after the large economic downturn of the early 1980s. The generalizability of our findings to more recent cohorts of school leavers is determined by comparability across cohorts and recessions. Second, our measures of sleep quality and quantity are reported by individuals. Although these measures are comparable with methods used to diagnose sleep problems by health-care professionals and measures used in previous sleep analyses, there may be remaining concerns regarding these measures. Third, our IVs are somewhat weak in some of the subsamples that we examine which may lead to bias.

In summary, we provide new information on the medium to long run implications of leaving school in a severe economic downturn. As such, our study extends the understanding of the consequences of leaving school in an economic downturn and adds to the literature on determinants of sleep outcomes.

\section{Acknowledgements}

We thank Douglas Webber and two anonymous Referees for helpful comments. All errors are our own. 


\section{Disclaimer:}

This research was conducted with restricted access to Bureau of Labor Statistics (BLS) data. The views expressed here do not necessarily reflect the views of the BLS.

\section{Appendix}

Table 26: School leaving cohort size by year: NLSY79.

\begin{tabular}{ll}
\hline School leaving year & Number of school leavers (unweighted) \\
\hline 1976 & 580 \\
1977 & 740 \\
1978 & 1,039 \\
1979 & 1,171 \\
1980 & 939 \\
1981 & 951 \\
1982 & 895 \\
1983 & 582 \\
1984 & 372 \\
1985 & 258 \\
1986 & 195 \\
1987 & 122 \\
1988 & 71 \\
1989 & 52 \\
1990 & 33 \\
1991 & 18 \\
1992 & 28 \\
1993 & 17 \\
1994 & 15 \\
1995 & 5 \\
1996 & 8 \\
1997 & 6 \\
1998 & 2 \\
Total & 8999 \\
\hline
\end{tabular}

Notes: A school leaving cohort is defined as individuals who left school in the same year. The sample includes one observation per respondent.

\section{Notes}

${ }^{1}$ The remaining time is allocated in the following manner: $2.8 \mathrm{~h}$ in leisure and sports activities, $0.9 \mathrm{~h}$ in household activities, and $3.2 \mathrm{in}$ other activities.

${ }^{2}$ http://www.thefiscaltimes.com/Articles/2012/07/23/Sleepless-in-America-A-32-4-Billion-Business; accessed January 25 th, 2016. Authors inflated the originally cited estimate (\$32.4B in 2012 dollars) to 2016 dollars using the Consumer Price Index - Urban Consumers.

${ }^{3}$ We direct interested readers to early economic insights on the optimal sleep allocation offered by El Hodiri (1973), Bergstrom (1976), and Hoffman (1977).

${ }^{4}$ Specifically, BH assume that there are two wage components: one that is unrelated to sleep and is instead determined by other factors unique to the individual; another is a "wage premium" that is attributable to sleep. In other words, sleep provides workers with a productivity bump on top of their fixed marginal product.

${ }^{5}$ Theoretical work by Asgeirsdottir and Zoega (2011) and Yaniv (2004) does address sleep quality. However, while both important and interesting, these models do not directly relate to the principle factors that we hypothesize link leaving school in an economic downturn and sleep outcomes. For brevity, we refer interested readers to these important studies, but we do not present their models here.

${ }^{6}$ Several economic studies have replicated the negative relationship between wages and sleep quantity (Szalontai 2006; Ásgeirsdóttir and Ólafsson 2015; Pfeifer 2015). The empirical economics literature offers mixed evidence as to whether sleep quantity is a normal good (Szalontai 2006; Antillón, Lauderdale, and Mullahy 2014; Pfeifer 2015). There are several economic studies that consider other factors related to (either causes of or consequences of) sleep. We refer interested readers to the work of Ásgeirsdóttir, Ólafsson, and Zoega (2015); Popovici and French (2013); and Jin and Ziebarth (2015). However, there is a surprising scarcity of economics studies examining sleep.

${ }^{7} \mathrm{~A}$ recent study by Speer (2016) finds severe, but ephemeral, reductions in hours and wages for lower skill workers. In particular, the negative effects dissipate after 1 year in the labor market. Moreover, among samples of college graduates, Oreopoulos, Von Wachter, and Heisz (2012) and Altonji, Kahn, and Speer (2016) show that higher skill workers may be sheltered from recession effects relative to less 
skilled workers. In general, the literature appears to suggest that, while effects are persistent for most groups of workers, they are not permanent and eventually workers are able to overcome the initial hurdle.

${ }^{8}$ The authors explore the persistent wage effects of leaving school in an economic downturn among Japanese men. They find a different pattern of results but attribute the findings to specific features of the Japanese labor market.

${ }^{9}$ In the BH model, the wage/income-sleep relationship is complicated and ex ante ambiguous because there are two wage effects (the standard wage rate and the wage premium attributable to sleep) and sleep enters directly into the consumer's utility function. We refer interested readers to the BH model for more details. Ásgeirsdóttir, Ólafsson, and Zoega (2015) develop a model of sleep which similarly complicates the wage-sleep relationship.

${ }^{10}$ We expect that, if present, this increase in working time to occur after the economy recovers (Kahn 2010). It seems unlikely that workers will be able to increase working time during the economic downturn faced at school leaving when employment prospects decline as firms demand less labor.

${ }^{11} \mathrm{An}$ important source of heterogeneity in the economic downturn-sleep relationship is the need for sleep across individuals (Ásgeirsdóttir, Ólafsson, and Zoega 2015). That is, some individuals require more sleep to work and conduct other activities productively. An obvious empirical solution to (time invariant) individual heterogeneity is inclusion of person fixed effects in the regression model. However, this approach is not possible in our study as our key predictor variable (the school leaving state unemployment rate) is fixed within individuals. We note the inability to control for such individual heterogeneity as a limitation of our study.

${ }^{12}$ According to the National Sleep Foundation, insomnia is defined as "difficulty falling asleep or staying asleep, even when a person has the chance to do so. People with insomnia can feel dissatisfied with their sleep and usually experience one or more of the following symptoms: fatigue, low energy, difficulty concentrating, mood disturbances, and decreased performance in work or at school" (https://sleepfoundation.org/insomnia/content/what-is-insomnia; accessed October 3rd, 2016).

${ }^{13}$ For example, if a respondent left school in 1994, we would not include the sleep variable measured in 1992.

${ }^{14}$ Given that $3 \%$ of Americans move across state lines in any given year historically (Bureau of the Census 1976), we suspect that this imputation does not lead to substantial measurement error. Results are robust if we exclude individuals who left school between 1976 and 1978 (those adults for whom we impute the school leaving state).

${ }^{15}$ However, the unemployment rate is but one proxy for economic conditions. In unreported analyses, we found similar results using the number of employed persons to proxy economic conditions.

${ }^{16}$ The AFQT was fielded in 1980 when respondents were 15-23 years of age. We might expect that older individuals will, all else equal, score higher on the AFQT than younger individuals. Therefore, we follow Kahn (2010) and age standardize the score in the following manner: $A F Q T_{\_}$stand $_{i g}=\left(A F Q T_{i}-\overline{A F Q T}_{g}\right) / A F Q T_{S D, g}$, where $\overline{A F Q T}_{g}$ is the mean AFQT score for age group $g, A F Q T_{S D, g}$ is the standard deviation of the AFQT score for age group $g$, and $g \in$ [15 years, 23 years]. A concern with including the AFQT score in our regressions is that it may be determined by economic conditions at school leaving because the test was fielded in 1980, a year in which some individuals in our sample left school (see Table 1). The AFQT may therefore be a "bad control" (Angrist and Pischke 2009). To explore this possibility, we estimated our regression models excluding the AFQT. Results, available on request, are not appreciably different than those reported in the manuscript.

${ }^{17}$ Ideally, we would like to utilize finer bins in the more distal periods (26-37 years after school leaving), but we lack sufficient data to create such bins.

${ }^{18}$ These estimates are available from the corresponding author.

${ }^{19}$ In unreported analyses, we included school-leaving state-specific linear time trends to the OLS regression model. Results are not appreciably different than those reported here.

${ }^{20}$ For example, if a respondent left school after completing 1 year of college (e. g. dropping out after the first year of college), we assume that this respondent left school at age 19 (the modal age for first year college students in the sample). We assign this respondent the annual state unemployment rate in the year she turned 19 in the state of residence at age 14. We make similar assignments for all individuals who left school without a credential. For a nonstandard credential (as previously defined), we make similar assignments. For example, we assume that an individual who left school with a 2-year college degree left school at age 20 as this is the modal age for individuals with a 2 -year associates degree. We assign this respondent the annual state unemployment rate in the year she turned 20 in the state of residence at age 14. Because we rely on years of schooling, there may be some reporting error in the actual level of education at school leaving, but what is important for the purposes of our study is the precise time at which the individual left school, which is more accurately reflected in years of schooling than, for example, information contained in questions pertaining to the highest level of education obtained. If we cannot locate the number of years of schooling, we rely on information on the highest level of education obtained as a proxy for the number of years to increase sample size. We assume that the respondent passed through the education system on time (e. g. 12 years of schooling for a high school diploma). Results are not substantially different from those reported here if we instead rely on only those respondents for whom we have years of schooling information.

${ }^{21}$ OLS results are similar and are available on request.

${ }^{22}$ Although previous studies have explored similar relationships (see Section 2.2), we wish to explore which of these specific pathways are important for our sample. Our intent is not to present these findings as new evidence, but rather to better understand the sleep effects that we document.

${ }^{23}$ A concern with our mechanism variables is reporting error. Because the NLSY79 commenced in 1979, we have no information on these mechanisms (or our other variables) before that year. However, as reported in Table 1, roughly $29 \%$ of our sample left school before 1979 . We are not able to include initial years post school leaving for these individuals. If the early years are important for our mechanisms, and our analyses and other studies suggest they are, then we will systematically measure these variables with error for members of our sample who left before and after 1979 (i. e. the former group will have missing information for the years between the school leaving year and 1979, while the latter group will not). Given that our primary explanatory variable (the school leaving state unemployment rate) is defined at the school leaving state and year level, this misreporting is particularly concerning from a bias perspective. If systematic measurement error in both dependent and independent variables can attenuate or amplify regression coefficients (Bound, Brown, and Mathiowetz 2001), it is difficult to even sign the bias attributable to such measurement error.

${ }^{24}$ Given that the inclusion of variables that are themselves likely outcomes of the treatment variable (e. g. the labor and marriage market measures) precludes a causal interpretation of regression coefficients, we chose to use OLS regressions in our decomposition analysis.

${ }^{25}$ Although we note that Kondo (2015) does not observe precisely estimated differences in wage effects between different racial groups in her study, the economic theory reviewed by Kondo opens the door for the possibility that there may be heterogeneity across race and ethnicity.

${ }^{26} \mathrm{~A}$ caveat to our analysis by skill level is that educational attainment at school leaving is potentially endogenous to the school leaving state unemployment rate. Readers should interpret findings generated in this analysis with some caution as stratifying the sample on an endogenous variable can lead to bias in regression coefficient estimates. A similar argument can be made for stratifying the sample on 
AFQT score. Nevertheless, in unreported analyses, we reestimated our analysis of heterogeneity by skill using father's education, which is arguably exogenous to the school leaving state unemployment rate and potentially proxies for worker skill or ability and results are similar. These results are available on request.

${ }^{27}$ Interpreting the findings by educational credentials at school leaving is somewhat complex, both in the context of studying sleep quality and sleep quantity. First, we combine workers with very different skill levels in these classifications. For example, the nonstandard educational credential sample includes workers with less than high school, some college (but not a 4-year college degree), and those with more than a 4-year college degree (e. g. a Ph.D. or M.D.). Both economic theory and previous analysis of the life course consequences of leaving school in an economic downturn will differ across these skill levels. However, we might also expect that the instrument is more or less suitable for these groups, thus leading to the differential findings. Interpretation of this margin of heterogeneity is further complicated as we work with a small sample, leaving us little power to detect effects. Finally, interpreting regression results based on samples that are stratified by an endogenous variable impedes the researcher's ability to interpret the regression coefficients causally.

${ }^{28}$ Authors' personal email communications with NLSY79 administrators on October 30, 2015.

${ }^{29}$ Recall that we are unable to measure labor market and marriage market experiences prior to 1979, the year in which the NLSY79 commenced, for those individuals who left school before 1979. For such individuals, these measures are cumulative from 1979 through the survey year in which the sleep variable is measured.

${ }^{30}$ One may wonder how it is possible to observe such different findings for men and women within the same cohort. We refer interested readers to Maclean, Covington, and Sikora Kessler (2015) for a full discussion. Broadly, the authors suggest that men and women marry out of cohort. On average, in an older cohort such as the NLSY79, men tend to marry younger women and women tend to marry older men. Thus, these differential marriage patterns may allow for differences across men and women in marriage and fertility outcomes within the same cohort.

${ }^{31}$ We note that this finding is not precisely estimated in the initial years after school leaving.

\section{References}

Acemoglu, D., J. Angrist, M. Bils, and C. E. Rouse. 2001. “How Large are Human-Capital Externalities? Evidence from Compulsory Schooling Laws." NBER Macroeconomics Annual 15: 9.

Altevogt, B. M., and H. R. Colten. 2006. Sleep Disorders and Sleep Deprivation:: An Unmet Public Health Problem. National Academies Press.

Altonji, J. G., L. B. Kahn, and J. D. Speer. 2014. “Cashier or Consultant? Entry Labor Market Conditions, Field of Study, and Career Success.” In NBER Working Paper Series, N. B. o. E. Research. Cambridge, MA: National Bureau of Economic Research.

Altonji, J. G., L. B. Kahn, and J. D. Speer. 2016. “Cashier or Consultant? Entry Labor Market Conditions, Field of Study, and Career Success.” Journal of Labor Economics 34 (S1):. S361-S401.

Angrist, J. D., and ]. Pischke. 2009. Mostly Harmless Econometrics: An Empiricist's Companion. Princeton, N]: Princeton University Press.

Antillón, M., D. S. Lauderdale, and J. Mullahy. 2014. “Sleep Behavior and Unemployment Conditions." Economics \& Human Biology 14: $22-32$.

Ásgeirsdóttir, T. L., H. Corman, K. Noonan, P. Ólafsdóttir, and N. E. Reichman. 2014. “Was the Economic Crisis of 2008 Cood for Icelanders? Impact on Health Behaviors." Economics \& Human Biology 13: 1-19.

Ásgeirsdóttir, T. L., H. Corman, K. Noonan, and N. E. Reichman. 2016. “Lifecycle Effects of a Recession on Health Behaviors: Boom, Bust, and Recovery in Iceland." Economics \& Human Biology 20: 90-107.

Ásgeirsdóttir, T. L., and S. P. Ólafsson. 2015. "An Empirical Analysis of the Demand for Sleep: Evidence from the American Time Use Survey." Economics \& Human Biology 19: 265-274.

Ásgeirsdóttir, T. L., S. P. Ólafsson, and C. Zoega. 2015. “Sleep and the Management of Alertness.” Mind \& Society 1-21. https://link.springer.com/article/10.1007/s11150-014-9272-7.

Asgeirsdottir, T. L., and C. Zoega. 2011. “On the Economics of Sleeping.” Mind \& Society 10 (2): 149-164.

Ayyagari, P., and D. M. Shane. 2015. “Does Prescription Drug Coverage Improve Mental Health? Evidence from Medicare Part D." Journal of Health Economics 41: 46-58.

Baldwin, D. C., and S. R. Daugherty. 2004. “Sleep Deprivation and Fatigue in Residency Training: Results of a National Survey of First- and Second-Year Residents." Sleep 27 (2): 217-223.

Becker, G. S 1965. "A Theory of the Allocation of Time." The Economic Journal 493-517. https://link.springer.com/article/10.1007/s11150-014-9272-7.

Bergstrom, T. C 1976. “Toward Deeper Economics of Sleeping." Journal of Political Economy 84 (2): 411-412.

Biddle, J. E., and D. S. Hamermesh. 1990. "Sleep and the Allocation of Time." The Journal of Political Economy 98 (5 Part 1): $922-943$.

Blau, F., and L. Kahn. 2007. “Changes in the Labor Supply Behavior of Married Women: 1980-2000." Journal of Labor Economics 25 (3): 393-438.

Blinder, A. S 1973. “Wage Discrimination: Reduced Form and Structural Estimates.” Journal of Human Resources 436-455. https://link.springer.com/article/10.1007/s11150-014-9272-7.

Bound, J., C. Brown, and N. Mathiowetz. 2001. “Chapter 59 Measurement Error in Survey Data." In Handbook of Econometrics., edited by ]. J. Heckman, and E. Leamer, Vol. 5, 3705-3843. Amsterdam, Netherlands: Elsevier.

Brochu, P., C. D. Armstrong, and L.-P. Morin. 2012. “The 'Trendiness' of Sleep: An Empirical Investigation into the Cyclical Nature of Sleep Time." Empirical Economics 43 (2): 891-913.

Bureau of Labor Statistics. 2015. “B. o. L. Statistics.” In American Time Use Survey-2014 Results Washington, DC: Bureau of Labor Statistics.

Bureau of the Census. 1976. "Statistical Abstract of the United States." In Statistical Abstract of the United States Washington, DC: Bureau of the Census.

Cameron, C. A., and D. L. Miller. 2015. “A Practitioner's Cuide to Cluster-Robust Inference." Journal of Human Resources 50 (2): 317-372.

Cappuccio, F. P., L. D’Elia, P. Strazzullo, and M. A. Miller. 2010. “Quantity and Quality of Sleep and Incidence of Type 2 Diabetes: A Systematic Review and Meta-Analysis." Diabetes Care 33 (2): 414-420. 
Carpenter, J. S., and M. A. Andrykowski. 1998. "Psychometric Evaluation of the Pittsburgh Sleep Quality Index." Journal of Psychosomatic Research 45 (1): 5-13.

Chong, Y., C. Fryar, and Q. Gu. (2013).Prescription Sleep Aid use among Adults: United States, 2005-2010 Hyattsville, MD: National Center for Health Statistics N. C. f. H. Statistics.

Cutler, D. M., W. Huang, and A. Lleras-Muney. 2015. "When Does Education Matter? The Protective Effect of Education for Cohorts Craduating in Bad Times." Social Science \& Medicine 127: 63-73.

Daley, M., C. M. Morin, M. LeBlanc, J. P. Gregoire, and ]. Savard. 2009. “The Economic Burden of Insomnia: Direct and Indirect Costs for Individuals with Insomnia Syndrome, Insomnia Symptoms, and Cood Sleepers." Sleep 32 (1): 55-64.

El Hodiri, M. 1973. “Unpublished manuscript.” In The Economics of Sleeping. University of Kansas.

Falba, T. A., J. L. Sindelar, and W. T. Callo. 2009. "Work Expectations, Realizations, and Depression in Older Workers." Journal of Mental Health Policy and Economics 12 (4): 175-186.

Friedman, E. M., G. D. Love, M. A. Rosenkranz, H. L. Urry, R. J. Davidson, B. H. Sfnger, and C. D. Ryff. 2007. “Socioeconomic Status Predicts Objective and Subjective Sleep Quality in Aging Women." Psychosomatic Medicine 69 (7): 682-691.

Cellis, L. A., K. L. Lichstein, I. C. Scarinci, H. H. Durrence, D. J. Taylor, A. J. Bush, and B. W. Riedel. 2005. “Socioeconomic Status and Insomnia.” Journal of Abnormal Psychology 114 (1): 111-118.

Genda, Y., A. Kondo, and S. Ohta. 2010. “Long-Term Effects of a Recession at Labor Market Entry in Japan and the United States." Journal of Human Resources 45 (1): 157-196.

Grandner, M. A., N. P. Patel, P. R. Gehrman, D. Xie, D. Sha, T. Weaver, and N. Gooneratne. 2010. “Who Gets the Best Sleep? Ethnic and Socioeconomic Factors Related to Sleep Complaints." Sleep Med 11 (5): 470-478.

Grossman, M 1972. "On the Concept of Health Capital and the Demand for Health." Journal of Political Economy 80 (2): 223-255.

Guo, N., and R. Hai. 2015. "SSRN Working Paper Series. SSRN, SSRN." In The Long-term Impact of an Early Career Recession on Health and HealthRelated Behaviors.

Hale, L 2005. “Who Has Time to Sleep?” Journal of Public Health 27 (2): 205-211.

Hershbein, B. ] 2012. “Graduating High School in a Recession: Work, Education, and Home Production." The B.E. Journal of Economic Analysis $\&$ Policy 12:. https://link.springer.com/article/10.1007/s11150-014-9272-7.

Hicks, R. A., K. Lindseth, and J. Hawkins. 1983. “Daylight Saving-Time Changes Increase Traffic Accidents.” Perceptual and Motor Skills 56 (1): 64-66.

Hill, T. D., A. M. Burdette, and L. Hale. 2009. “Neighborhood Disorder, Sleep Quality, and Psychological Distress: Testing a Model of Structural Amplification." Health \& Place 15 (4): 1006-1013.

Hill, T. D., H. N. Trinh, M. Wen, and L. Hale. 2014. “Perceived Neighborhood Safety and Sleep Quality: A Clobal Analysis of Six Countries.” Sleep Medicine, https://link.springer.com/article/10.1007/s11150-014-9272-7.

Hoffman, E. P 1977. "The Deeper Economics of Sleeping: Important Clues toward the Discovery of Activity X." The Journal of Political Economy 647-649. https://link.springer.com/article/10.1007/s11150-014-9272-7.

Hofmann, B., and K. Hohmeyer. 2014. "The Effect of the Business Cycle at College Graduation on Fertility.", https://link.springer.com/article/10.1007/s11150-014-9272-7.

Jin, L., and N. R. Ziebarth. (2015).Sleep and Human Capital: Evidence from Daylight Saving Time HEDG, c/o Department of Economics, University of York.

Kahn, L. B 2010. “The Long-Term Labor Market Consequences of Graduating from College in a Bad Economy.” Labour Economics 17 (2): 303-316.

Kaneita, Y., E. Yokoyama, S. Harano, T. Tamaki, H. Suzuki, T. Munezawa, H. Nakajima, T. Asai, and T. Ohida. 2009. “Associations between Sleep Disturbance and Mental Health Status: A Longitudinal Study of Japanese Junior High School Students." Sleep Medicine 10 (7): 780-786.

King, C. R., K. L. Knutson, P. J. Rathouz, S. Sidney, K. Liu, and D. S. Lauderdale. 2008. “Short Sleep Duration and Incident Coronary Artery Calcification." JAMA 300 (24): 2859-2866.

Kirby, J. B., G. Taliaferro, and S. H. Zuvekas. 2006. “Explaining Racial and Ethnic Disparities in Health Care.” Medical Care 44 (5):. I-64-I-72.

Knipling, R., and J. Wang. 1994. Crashes and Fatalities Related to Driver Drowsiness/Fatigue. Washington, DC: Department of Transportation, National Highway Traffic Safety Administration.

Knutson, K. L., E. Van Cauter, P. J. Rathouz, T. DeLeire, and D. S. Lauderdale. 2010. “Trends in the Prevalence of Short Sleepers in the USA: 1975-2006." Sleep 33 (1): 37-45.

Kohout, F. J., L. F. Berkman, D. A. Evans, and ]. Cornoni-Huntley. 1993. "Two Shorter Forms of the CES-D Depression Symptoms Index." Journal of Aging and Health 5 (2): 179-193.

Kondo, A 2015. "Differential Effects of Graduating during a Recession across Gender and Race." IZA Journal of Labor Economics 4 (1): 1-24.

Krueger, P. M., and E. M. Friedman. 2009. "Sleep Duration in the United States: A Cross-Sectional Population-Based Study." American Journal of Epidemiology 169 (9): 1052-1063.

Kutner, N. G., D. L. Bliwise, D. Brogan, and R. Zhang. 2001. “Race and Restless Sleep Complaint in Older Chronic Dialysis Patients and Nondialysis Community Controls." The Journals of Cerontology Series B: Psychological Sciences and Social Sciences 56 (3):. P170-P175.

Kwon, I., E. M. Milgrom, and S. Hwang. 2010. “Cohort Effects in Promotions and Wages." Journal of Human Resources 45 (3): 772-808.

Landrigan, C. P., J. M. Rothschild, J. W. Cronin, R. Kaushal, E. Burdick, J. T. Katz, C. M. Lilly, P. H. Stone, S. W. Lockley, and D. W. Bates. 2004. “Effect of Reducing Interns' Work Hours on Serious Medical Errors in Intensive Care Units." New England Journal of Medicine 351 (18): 1838-1848.

Lauderdale, D. S., K. L. Knutson, L. J. L. Yan, P. J. Rathouz, S. B. Hulley, S. Sidney, and K. Liu. 2006. “Objectively Measured Sleep Characteristics among Early-Middle-Aged Adults - the CARDIA Study." American Journal of Epidemiology 164 (1): 5-16.

Liu, K., K. G. Salvanes, and E. Sorensen. (2012).Good Skills in Bad Times: Cyclical Skill Mismatch and the Long-term Effects of Craduating in a Recession NHH Dept. of Economics Discussion Paper(16). 
Lombardi, D. A., A. Wirtz, J. L. Willetts, and S. Folkard. 2012. “Independent Effects of Sleep Duration and Body Mass Index on the Risk of a Work-Related Injury: Evidence from the US National Health Interview Survey (2004-2010)." Chronobiology International 29 (5): 556-564.

Maclean, J. C 2013. "The Health Effects of Leaving School in a Bad Economy." Journal of Health Economics 32 (5): 951-964.

Maclean, J. C 2014. “Does Leaving School in an Economic Downturn Impact Access to Employer-Sponsored Health Insurance?” IZA Journal of Labor Policy 3 (1): 1-27.

Maclean, J. C 2015. “The Lasting Effects of Leaving School in an Economic Downturn on Alcohol Use.” ILR Review 68 (1): 120-152.

Maclean, J. C 2016. "Does Leaving School in an Economic Downturn Persistently Affect Body Weight? Evidence from Panel Data." Industrial Relations: A Journal of Economy and Society 55 (1): 122-148.

Maclean, J. C., R. Covington, and A. Sikora Kessler. 2015. “Contemporary Economic Policy: n/a-n/a.” In Labor Market Conditions at SchoolLeaving: Long-Run Effects on Marriage and Fertility.

Maclean, J. C., and T. D. Hill. 2015. "Leaving School in an Economic Downturn and Self-Esteem across Early and Middle Adulthood." Labour Economics 37: 1-12.

Mansour, H. unpublished manuscript. 2009. The Career Effects of Craduating from College in a Bad Economy: The Role of Workers' Ability. University of Denver.

Mclnerney, M., J. M. Mellor, and L. H. Nicholas. 2013. “Recession Depression: Mental Health Effects of the 2008 Stock Market Crash.” Journal of Health Economics 32 (6): 1090-1104.

McLaughlin, K. J., and M. Bils. 2001. "Interindustry Mobility and the Cyclical Upgrading of Labor.” Journal of Labor Economics 19 (1): 94-135.

Monk, T. H 1980. "Traffic Accident Increases as a Possible Indicant of Desynchronosis." Chronobiologia, https://link.springer.com/article/10.1007/s11150-014-9272-7.

Moore, P. J., N. E. Adler, D. R. Williams, and ]. S. Jackson. 2002. "Socioeconomic Status and Health: The Role of Sleep." Psychosomatic Medicine 64 (2): $337-344$.

National Bureau of Economic Research. 2010. U.S. Business Cycle Expansions and Contractions Cambridge, MA: National Bureau of Economic Research.

National Institutes of Health. 2012. "Diagnosing Sleep Disorders." In NIH Medline Plus: The magazine. 7.

National Sleep Foundation. 2015. December 6 2015. https://sleepfoundation.org/.

Neumark, D 1988. “Employers' Discriminatory Behavior and the Estimation of Wage Discrimination." Journal of Human Resources 279-295. https://link.springer.com/article/10.1007/s11150-014-9272-7.

Oaxaca, R 1973. “Male-Female Wage Differentials in Urban Labor Markets." International Economic Review 693-709. https://link.springer.com/article/10.1007/s11150-014-9272-7.

Okun, A. M 1973. "Upward Mobility in a High-Pressure Economy." Brookings Papers on Economic Activity 1: 207-261.

Oreopoulos, P., T. Von Wachter, and A. Heisz. 2012. "The Short- and Long-Term Career Effects of Graduating in a Recession." American Economic Journal: Applied Economics 4 (1): 1-29.

Oyer, P 2006. “Initial Labor Market Conditions and Long-Term Outcomes for Economists.” The Journal of Economic Perspectives 20 (3): 143-160.

Oyer, P 2008. "The Making of an Investment Banker: Stock Market Shocks, Career Choice, and Lifetime Income." The Journal of Finance 63 (6): 2601-2628.

Pabilonia, S. W. 2014. “IZA Discussion Paper. IZA, IZA." In The Effects of the Great Recession on Teenagers' Risky Health Behaviors and Time Use.

Paine, S. J., P. H. Gander, R. Harris, and P. Reid. 2004. "Who Reports Insomnia? Relationships with Age, Sex, Ethnicity, and Socioeconomic Deprivation." Sleep 27 (6): 1163-1169.

Pfeifer, C. 2015. “IZA Discussion Papers, IZA.” In Unfair Wage Perceptions and Sleep: Evidence from Cerman Survey Data.

Popovici, I., and M. T. French. 2013. “Binge Drinking and Sleep Problems among Young Adults." Drug and Alcohol Dependence 132 (1-2): 207-215.

Powell, L. M., R. Wada, R. C. Krauss, and Y. Wang. 2012. “Ethnic Disparities in Adolescent Body Mass Index in the United States: The Role of Parental Socioeconomic Status and Economic Contextual Factors." Social Science \& Medicine 75 (3): 469-476.

Powell, N. B., K. B. Schechtman, R. W. Riley, K. Li, R. Troell, and C. Guilleminault. 2001. “The Road to Danger: The Comparative Risks of Driving while Sleepy." The Laryngoscope 111 (5): 887-893.

Radloff, L. S 1977. “The CES-D Scale a Self-Report Depression Scale for Research in the General Population." Applied Psychological Measurement 1 (3): 385-401.

Reder, M. W 1955. “The Theory of Occupational Wage Differentials.” American Economic Review 45 (5): 833-852.

Redline, S., and A. B. Newman. 2002. “The Relationship between Chronically Disrupted Sleep and Healthcare Use.” Sleep 25 (3): 289.

Roehrs, T., and T. Roth. 2001. "Sleep, Sleepiness, Sleep Disorders and Alcohol Use and Abuse." Sleep Medicine Reviews 5 (4): $287-297$.

Sabia, J. J., and D. I. Rees. 2015. "Body Weight, Mental Health Capital, and Academic Achievement." Review of Economics of the Household 1-32. https://link.springer.com/article/10.1007/s11150-014-9272-7.

Schoar, A., and L. Zuo. 2011. "Shaped by Booms and Busts: How the Economy Impacts CEO Careers and Management Styles." In NBER Working Paper Series. Cambridge, MA: National Bureau of Economic Research, https://link.springer.com/article/10.1007/s11150-014-9272-7.

Solon, G., S. J. Haider, and J. M. Wooldridge. 2015. “What Are We Weighting For?” Journal of Human Resources 50 (2): 301-316.

Soltani, M., M. R. Haytabakhsh, J. M. Najman, G. M. Williams, M. J. O’Callaghan, W. Bor, K. Dingle, and A. Clavarino. 2012. “Sleepless Nights: The Effect of Socioeconomic Status, Physical Activity, and Lifestyle Factors on Sleep Quality in a Large Cohort of Australian Women." Arch Womens Ment Health 15 (4): 237-247.

Speer, J. D 2016. “Wages, Hours, and the School-To-Work Transition: The Consequences of Leaving School in a Recession for Less-Educated Men." The BE Journal of Economic Analysis \& Policy 16 (1): 97-124.

Stamatakis, K. A., G. A. Kaplan, and R. E. Roberts. 2007. “Short Sleep Duration across Income, Education, and Race/Ethnic Croups: Population Prevalence and Growing Disparities during 34 Years of Follow-Up." Annals of Epidemiology 17 (12): 948-955.

Stock, J. H., and M. Yogo. 2005. “Testing for Weak Instruments in Linear IV Regression." In Identification and Inference for Econometric Models: Essays in Honor of Thomas Rothenberg., edited by W.K. Donald, and James H. Stock.

Szalontai, G 2006. “The Demand for Sleep: A South African Study.” Economic Modelling 23 (5): 854-874. 
Williamson, A. M., and A.-M. Feyer. 2000. “Moderate Sleep Deprivation Produces Impairments in Cognitive and Motor Performance Equivalent to Legally Prescribed Levels of Alcohol Intoxication." Occupational and Environmental Medicine 57 (10): 649-655.

Yaniv, G 2004. “Insomnia, Biological Clock, and the Bedtime Decision: An Economic Perspective.” Health Economics 13 (1): 1-8. 